\title{
3 Phänomenbereich: drei Reflexivkonstruktionen
}

Die Entwicklung einer Konstruktionssemantik kann nicht abgekoppelt von konkreten sprachlichen Phänomenen stattfinden. Bevor in den Kapiteln 4 bis 8 die fünf in der Einleitung (Kapitel 1) formulierten Fragestellungen adressiert und einzelne Aspekte einer Konstruktionssemantik in den Blick genommen werden sollen, möchte ich in diesem Kapitel die drei Reflexivkonstruktionen vorstellen, die den empirischen Phänomenbereich der vorliegenden Arbeit bilden. Ziel ist es, anhand dieser Daten zentrale Bausteine einer Konstruktionssemantik herauszuarbeiten und deren Potenzial für konstruktikographische Analysen syntaktischer Konstruktionen zu illustrieren. Nicht zuletzt aus letzterem Grund wähle ich als Phänomenbereich drei deutsche Äquivalente einer Konstruktion, die zumindest für das Englische bereits mehr oder weniger ausführlich beschrieben worden ist und in der Literatur (ebenfalls für das Englische) eine der wenigen Konstruktionen ist, die des Öfteren mit einem Frame in Verbindung gebracht wird. Es handelt sich um die unter anderem von Goldberg (1995: 199-218, 1996) prominent untersuchte way-Konstruktion, die insbesondere in der Konstruktikographie, wie bereits in Unterabschnitt 2.3.2 gesehen, etwa bei Fillmore, Lee-Goldman \& Rhomieux (2012: 322) und Lee-Goldman \& Petruck (2018: 32-33), als beliebtes Beispiel für eine ,frame-evozierende‘ Konstruktion herangezogen wird.

Für das Deutsche lassen sich mindestens drei Äquivalente zu dieser Konstruktion finden, auf die ich in der vorliegenden Arbeit als reflexive Bewegungskonstruktion, reflexive Partikelverbkonstruktion und reflexive Weg-Konstruktion Bezug nehme. In den Abschnitten 3.1, 3.2 und 3.3 möchte ich diese drei Konstruktionen in dieser Reihenfolge vorstellen. Die reflexive Bewegungskonstruktion betrachte ich als primäres Äquivalent zur way-Konstruktion, während die beiden anderen Konstruktionen eher als zu Ersterer verwandt eingestuft werden können, nicht zuletzt aufgrund ihrer Rollen in der bisherigen (nicht nur konstruktionsgrammatischen) Forschung. Zum Abschluss dieses Kapitels stelle ich in Abschnitt 3.4 die Datengrundlage für die Untersuchung der drei Konstruktionen in Form des verwendeten Korpus vor und erläutere die manuelle Datenauswahl, die nötig ist, um aus den Treffern der für jede Konstruktion exhaustiven Suchanfragen relevante Belege herauszufiltern.

Selbstverständlich kann der umfangreiche Erklärungsanspruch, den eine elaborierte Konstruktionssemantik im Idealfall vertreten sollte, nicht allein anhand von drei einzelnen Konstruktionen erschöpfend eingelöst werden. Da die drei untersuchten Konstruktionen zudem formal und semantisch eng verwandt sind, kann der hier entwickelte Ansatz zunächst allein für diesen vergleichsweise kleinen Phänomenbereich Geltung beanspruchen. Zukünftige Studien werden 
den Ansatz auf Konstruktionen gänzlich anderer Art übertragen und seine Anwendbarkeit einer kritischen Prüfung unterziehen müssen. Ich betrachte die empirischen Analysen deshalb als ersten Dreh- und Angelpunkt einer theoretischen und methodologischen Entwicklung, die in noch umfangreicherem Maße ausgeweitet werden muss. Es ist nicht nur nicht auszuschließen, sondern sogar sehr wahrscheinlich, dass sich einzelne theoretische Aspekte im Hinblick auf andere Konstruktionen anders darstellen oder der methodische Zugang modifiziert werden muss.

\subsection{Reflexive Bewegungskonstruktion}

Bei der reflexiven Bewegungskonstruktion handelt es sich wie bei der wayKonstruktion um eine Argumentstruktur-Konstruktion. Die Tatsache, dass für die way-Konstruktion vor allem im Rahmen der Konstruktikographie bereits ein Bezug zu Frames hergestellt wurde und dass es sich bei ArgumentstrukturKonstruktionen seit Goldberg (1995) um den wohl mit Abstand am besten erforschten Gegenstand in der Konstruktionsgrammatik handelt, mag zunächst die Frage aufwerfen, warum der initiale Entwurf einer Konstruktionssemantik gerade solche Konstruktionen fokussieren muss (vgl. zu einer ähnlichen Kritik auch Stefanowitsch 2011: 17-18; Hilpert 2019: 57). Gerade den Umstand, dass Argumentstruktur-Konstruktionen aber am deutlichsten zeigen, dass syntaktischen Strukturen semantische Eigenschaften zugeschrieben werden können, die sich von denen, die etwa LE zukommen, nicht grundsätzlich unterscheiden müssen (vgl. Abschnitt 4.3), sehe ich als Argument dafür an, ArgumentstrukturKonstruktionen wie die drei untersuchten zum empirischen Phänomenbereich der vorliegenden Arbeit zu machen. Ein Vergleich mit anderen Arten von Konstruktionen macht das deutlich: So scheiden LE als lexikalische Konstruktionen aus, weil die bisher vorhandenen Mittel von FrameNet tendenziell ausreichen, die Basis ihrer lexikalischen Bedeutungen zu erfassen. Ihnen entgegengesetzt stehen Phänomene wie Mehrworteinheiten, Funktionsverbgefüge und Phraseme, die unterschiedlichste Herausforderungen an eine Konstruktionssemantik stellen. Ein Kompromiss besteht darin, zusätzlich zu einer Ausgangskonstruktion, hier also der reflexiven Bewegungskonstruktion, weitere, in ihren (formalen wie semantischen) Eigenschaften verwandte Konstruktionen einzubeziehen, die sich in den Ergebnissen einer konstruktionssemantischen Analyse aber teils mehr, teils weniger von ihr unterscheiden. Ich ziehe aus diesem Grund die reflexive Partikelverbkonstruktion (Abschnitt 3.2) und die reflexive Weg-Konstruktion (Abschnitt 3.3) heran, um sie mit der reflexiven Bewegungskonstruktion vergleichen und konstruktionssemantisch weiterführende Aspekte aufzeigen zu können. 
Das englische Pendant der drei untersuchten Konstruktionen und insbesondere der reflexiven Bewegungskonstruktion, die way-Konstruktion, ist, das legen die bisherigen Ausführungen nahe, ,perhaps the most studied and best understood construction and something of a poster boy of Construction Grammar." (Szcześniak 2014b: 153). Sie gehört bereits zu den von Goldberg (1995) herangezogenen Argumentstruktur-Konstruktionen, die ein Beispiel für die Existenz autonomer semantischer Eigenschaften von Konstruktionen sind, denn ,[t]he construction's semantics cannot be fully predicted on the basis of the constituent parts of the construction.“ (Goldberg 1995: 199). Darauf, dass sie im Deutschen einer Reflexivkonstruktion entspricht, ${ }^{1}$ haben bereits Kunze (1995) und Oya (1999) hingewiesen. ${ }^{2}$ In Übereinstimmung mit Oya (1999: 358) bezeichne ich sie deshalb als reflexive Bewegungskonstruktion (RBKxn). ${ }^{3}$ Einige Konstrukte finden sich in den Belegen in (1)-(10), die dem DWDS-Kernkorpus 21 entnommen sind.

Seitdem \{arbeitet sich der Professor acht Monate im Jahr mit einem Jeep durch die Wüste von Turkmenistan\}, harrt in Kasachstan stundenlang in ungeheizten Sitzungszimmern aus und bewahrt in Usbekistan auch nach dem sechsten Wodka noch die Contenance. (Die Zeit, 24.02.2000, Nr. 9)

1 Von einer Reflexivkonstruktion ist - im Gegensatz zu einem ,reflexiven Verb“ - laut Ágel (1997a: 181) dann zu sprechen, wenn sich das Auftreten des Reflexivums „nur konfigurationell ableiten läßt“. Aus konstruktionsgrammatischer Sicht ist dies jedoch kein notwendiges Kriterium, da auch Verben, für die ein Reflexivum „paradigmenkategoriell vorgesehen ist“ (Ágel 1997a: 181) als (lexikalische) Konstruktionen aufzufassen sind.

2 Eine strukturell analoge Reflexivkonstruktion existiert allerdings auch im Englischen, für die Mondorf (2011: 412) und Szcześniak (2019b: 82-95) (teils diachron) funktionale Arbeitsteilungen mit der way-Konstruktion feststellen. Ähnliches spekuliert bereits van Egmond (2009: 161-163) für eine Reihe germanischer Sprachen, darunter Deutsch. Goldberg \& Jackendoff (2004: 535) ziehen ebenso eine Parallele zwischen der way-Konstruktion und Reflexivkonstruktionen in unterschiedlichen germanischen Sprachen (allerdings ohne das Deutsche zu erwähnen). McColm (2019: 168-172) analysiert Verbindungen zwischen der way-Konstruktion und einer englischen Reflexivkonstruktion als Kontaminationen. Szcześniak \& Callies (2008: 33) parallelisieren die way-Konstruktion mit Konstruktionen um Präfixverben mit er-. Pedersen (2013: 244-249) findet in parallelen Korpora noch weitere mögliche Äquivalente, die ich aber, ebenso wie die von Szcześniak \& Callies (2008: 33) diskutierten Fälle, für die Zwecke der vorliegenden Arbeit ignoriere. Für einen Vergleich deutscher und englischer Reflexivkonstruktionen mit der way-Konstruktion vgl. Boas \& Ziem (2018b: 212-214).

3 Analog nutzen auch Perek \& Hilpert (2014: 270) und Boas \& Ziem (2018b: 211) sowie für das schwedische Äquivalent der way-Konstruktion Ehrlemark, Johansson \& Lyngfelt (2016: 816) Bezeichnungen wie reflexive-motion (construction). Welke (2011: 217) bezeichnet sie als reflexive Direktivkonstruktion, womit er ihre Verwandtschaft zu Caused-Motion- oder Resultativkonstruktionen betont, in deren Zusammenhang die way-Konstruktion bisweilen analysiert wird, z.B. bei Szcześniak \& Callies (2008), Mondorf (2011) oder Szcześniak (2013). 
(2) Der Fabrikant breitete sein Schweigen wieder aus, \{der Offizier mogelte sich aus seinem Sitz\}. (Düffel, John von: Vom Wasser, München: dtv 2006, S. 56)

(3) \{Mancher Programmdirektor wünscht sich hier inzwischen auf eine wirklich einsame Insel\}. (Die Zeit, 30.03.2000, Nr. 14)4

(4) Marie saß seit dem späten Nachmittag an ihrem kleinen Schreibtisch in ihrem Zimmer und \{kämpfte sich durch Theodor Fontanes Der Stechlin\}, über den sie eine Arbeit schreiben mußte. (Suter, Martin: Lila, Lila, Zürich: Diogenes 2004, S. 47)

(5) Als ich Tina kennenlernte, gingen wir zwar ein- oder zweimal zu viert essen, aber die Gespräche kamen nicht in Gang, \{man quälte sich durch typische Konversationsthemen wie Tagespolitik, neue Bücher, alte Gemälde und schlechtes oder gutes Wetter und die Auswirkungen all dessen auf die Gelenke\}. (Goosen, Frank: Liegen lernen, Frankfurt am Main: Eichborn AG 2000, S. 238)

(6) \{Stimmen mischten sich in das Rattern\}, Worte, Sätze, die sie nicht verstand, weil ihr Kopf so verschwommen war. (Pressler, Mirjam: Malka Mai, Weinheim Basel: Beltz \& Gelberg 2001, S. 248)

(7) Die Babylonier nickten und qquetschten sich ungelenk durch die Glastür auf die Steinstraße\}. (Kopetzky, Steffen: Grand Tour, Frankfurt am Main: Eichborn 2002, S. 283)

(8) Ich arbeitete gut und konzentriert; ich hatte Kräfte für zehn - und doch schlugen mir die Knie aneinander, als ich in die Allee einbog, und meine Hände gruben sich in die Rocktaschen\}, bis sie beinahe rissen. (Schmitter, Elke: Frau Sartoris, Berlin: BvT 2000[2002], S. 29)

(9) \{Mommsen rettete sich aus der Welt der Tatsachen in die der Gefühle\}: (de Bruyn, Günter: Preußens Luise, Siedler 2001, S. 87)

(10) Es war allen Anwesenden nachzufühlen; von unschuldigem Frohsinn war nichts zu spüren, die Abende zogen sich dahin, der Steuereintreiber und der Chirurg entschuldigten sich schon früh, um nicht wieder in den Genuß von Gratiskonsultationen zu kommen, der Priester gab seine zwei Witze zum besten, und der Rest lästerte über das Essen und ssoff sich unter den Tisch\}, weil selbst die Konjunktur als Thema längst ausgeschöpft war.

4 Es ist offensichtlich, dass in Belegen wie diesem eine,Bewegung nur metaphorisch verstanden werden kann. Der Einbezug einer metapherntheoretischen Komponente in eine Konstruktionssemantik ist ein Desiderat, das im Rahmen der vorliegenden Arbeit ausgeklammert werden muss. Ich komme darauf als Ausblick am Ende der Arbeit (Kapitel 9) zu sprechen. 
(Schrott, Raoul: Tristan da Cunha oder die Hälfte der Erde; Hanser Verlag 2003, S. 196)

Sowohl in formaler als auch in semantischer Hinsicht weist die reflexive Bewegungskonstruktion einige Unterschiede zum Englischen auf, weshalb Boas \& Ziem (2018b: 211-214) sie auf einem ,Kontinuum der Konstruktionskorrespondenzen' zwischen dem Deutschen und dem Englischen eher am ,nicht übereinstimmenden Ende‘ lokalisieren. Eine Parallele, die für die folgenden Überlegungen zentral ist, ist allerdings gegeben: Wie es Fillmore, Lee-Goldman \& Rhomieux (2012: 322) für die englische Konstruktion annehmen, ${ }^{5}$ kann auch ihr deutsches Äquivalent mit dem Frame Motion assoziiert werden, den ich in Unterabschnitt 2.1.2 vorgestellt habe. Die Strukturelemente der reflexiven Bewegungskonstruktion sollten sich, so die Annahme, prinzipiell wie diejenigen der way-Konstruktion auf FE dieses Frames beziehen lassen (vgl. Fillmore, Lee-Goldman \& Rhomieux 2012: 322; Boas 2014: 49, 2017: 568). Dies kommt nicht von ungefähr, denn bereits die way-Konstruktion kann als ein klassisches Phänomen gelten, die Strukturparallelen zwischen Konstruktionen und Frames zu eruieren, zumal sie schon außerhalb konstruktionsgrammatischer Theoriebildung als Paradefall für das Mapping einer konzeptuellen (d.h.: semantischen) Struktur auf eine syntaktische Struktur gilt (z.B. Jackendoff 1990: 218-223; Marantz 1992: 180).

Für die einführende Vorstellung der reflexiven Bewegungskonstruktionen gehe ich wie folgt vor: In Unterabschnitt 3.1.1 gebe ich einen Überblick über die bisherige Forschung. Danach nehme ich in Unterabschnitt 3.1.2 eine vorläufige Beschreibung der vier Strukturelemente der Konstruktion vor, bevor ich in Unterabschnitt 3.1.3 auf eine ihrer zentralen semantischen Eigenschaften, nämlich die bereits für die way-Konstruktion diskutierte konstruktionelle Polysemie, zu sprechen komme, die sich für die reflexive Bewegungskonstruktion und ihre beiden verwandten Konstruktionen ebenso feststellen lässt. In Unterabschnitt 3.1.4 betrachte ich ausgehend von der Forschung zur way-Konstruktion einige für diese formulierte semantische Beschränkungen und setze mich kritisch mit deren bisheriger Diskussion und ihrer möglichen Übertragbarkeit auf die reflexive Bewegungskonstruktion auseinander. In Unterabschnitt 3.1.5 skizziere ich die Verwandtschaft der reflexiven Bewegungskonstruktion zu den beiden anderen untersuchten Konstruktionen, der reflexiven Partikelverbkonstruktion und der reflexiven Weg-Konstruktion. Besonders die Fragen nach der konstruktionellen Polyse-

5 Wie bereits in Unterabschnitt 2.3.2 erwähnt, analysieren Lee-Goldman \& Petruck (2018: 32-33) die way-Konstruktion demgegenüber mit Self_motion, und auch die Datenbank des FrameNetKonstruktikons ist in dieser Hinsicht inkonsistent. Eine ausführliche methodische Begründung, warum ich auf Motion zurückgreife, findet sich in Unterabschnitt 8.5.1. 
mie und den semantischen Beschränkungen der reflexiven Bewegungskonstruktion lassen sich grundsätzlich auch auf diese beiden Konstruktionen übertragen, weshalb ich bei deren Vorstellung (Abschnitte 3.2 und 3.3) nicht noch einmal darauf zurückkomme, sondern dort insbesondere die strukturellen Unterschiede zur reflexiven Bewegungskonstruktion herausstelle.

\subsubsection{Forschungsstand}

Im Gegensatz zu ihrem englischen Pendant hat die reflexive Bewegungskonstruktion bisher verhältnismäßig wenig explizite Aufmerksamkeit der Forschung erfahren, sowohl innerhalb als auch außerhalb der Konstruktionsgrammatik. Aus konstruktionsgrammatischer Perspektive ist sie - trotz der hohen Prominenz der way-Konstruktion - kaum in den Blick genommen worden. Gleiches gilt im Übrigen (zum Teil noch stärker) für die reflexive Partikelverbkonstruktion und die reflexive Weg-Konstruktion.

Noch ohne die Konstruktion zu benennen oder auf ihre Äquivalenz zur wayKonstruktion hinzuweisen, ${ }^{6}$ diskutiert Seibert (1993) ein Konstrukt der reflexiven Bewegungskonstruktion im Kontext von Resultativkonstruktionen. Dabei hält sie fest, dass die obligatorisch auftretende PP, die sie als Resultativprädikat interpretiert, „specifies a result that is external to the criteriality of the verb“ (Seibert 1993: 66), womit sie bereits andeutet, dass mindestens zwei semantische Eigenschaften, diejenigen des Verbs und diejenigen einer Konstruktion, zusammenkommen müssen. Eine vergleichbar frühe Studie von Maienborn (1994) weist auf die mögliche Kookkurrenz von Verben, in deren lexikalischer Bedeutung keine ,Bewegung“ angelegt ist, mit direktionalen Präpositionen hin, wodurch jeweils „ein temporäres Bewegungsverb geschaffen“ (Maienborn 1994: 239) wird.7 Maienborn arbeitet (von außen betrachtet), ähnlich wie Seibert, unabhängig von Beobachtungen zum Englischen, obwohl sie die semantischen Eigenschaften der Konstruktion ähnlich wie Jackendoff (1990: 211-223) für die way-Konstruktion durch formale Repräsentationen zu erklären sucht. Wenig später nimmt Kunze (1995: 24-26) erstmals expliziten Bezug auf die Beschreibung der way-Konstruktion durch Jackendoff (1990: 211-223). Auch Kunze (1997: 97-98) geht wie Maienborn davon aus,

6 Vgl. dazu van Egmond (2009: 162): „Seibert (1993) provides the example [...] outside the context of the way-constrution."

7 Diese Auffassung entspricht dem später von Goldberg (1995: 9) kritisierten Verfahren des Ansetzens von „implausible verb senses“. Diese Haltung wiederum wird von Boas (2002, 2003a,b) kritisiert, der stattdessen das Konzept der Mini-Konstruktionen, die eine solche Verbpolysemie abbilden können, entwickelt (vgl. Unterabschnitte 2.2.3 und 2.2.4). 
dass die lexikalische Bedeutung eines Verbs durch die Verwendung mit einem Reflexivum und einer direktionalen PP modifiziert wird.

Als explizites Äquivalent zur way-Konstruktion diskutiert erst Oya (1999) die reflexive Bewegungskonstruktion und geht ausführlich auf die Analyse von Goldberg (1995: 199-218) ein. Für die semantische Beschreibung der Konstruktion wenden sowohl Kunze (1995) als auch Oya (1999) neben Paraphrasen die konzeptuelle Semantik von Jackendoff (1990) an. Die Studien von Kunze und Oya sind zudem nicht gebrauchsbasiert angelegt, sondern arbeiten fast ausschließlich mit konstruierten Belegen, an denen die Eigenschaften der way-Konstruktion auf Gemeinsamkeiten und Unterschiede zur deutschen Konstruktion überprüft werden. Nur konstruierte Belege verwenden auch Perek \& Hilpert (2014) in einer kontrastiven Analyse zum Englischen und Französischen, um die Akzeptabilität bestimmter als ,unüblich‘ empfundener Konstrukte experimentell zu überprüfen. Eine genuin korpusbasierte Analyse legt erst Smirnova (2018) vor, die in diesem Zusammenhang auch Kriterien für die Auswahl relevanter Konstrukte diskutiert, deren Formulierung sich bisweilen schwierig darstellt (dazu Unterabschnitt 3.4.2). Eine Anschlusstudie von Mortelmans \& Smirnova (2020) legt den Fokus auf einen Vergleich der englischen Konstruktion mit ihren Pendants im Deutschen und Niederländischen. ${ }^{8}$ Sie differenzieren zwei deutsche Äquivalente:

On the one hand, there is the schematic and relatively productive reflexive construction [...] which accommodates non-reflexive verbs in its verb slot. On the other hand, there are numerous lexical verbs which obligatorily feature a weak reflexive, [...]. (Mortelmans \& Smirnova 2020: 62)

Diese Differenzierung nehme ich nicht vor, sondern gehe davon aus, dass beide Arten von Instanzen als Konstrukte der reflexiven Bewegungskonstruktion betrachtet werden können, ${ }^{9}$ die sich darin unterscheiden, ob das in ihnen instanziierte Verb einen zu Motion in einer Frame-zu-Frame-Relation stehenden Frame evoziert oder einen, der in keiner Frame-zu-Frame-Relation zu Motion steht (dazu Abschnitt 5.4)..$^{10}$

Korpusbasiert geht ebenfalls die Studie von McColm (2019) vor, welche die erste monographische Arbeit zur way-Konstruktion und ihren Äquivalenten im Niederländischen und Deutschen darstellt. McColm betrachtet allerdings nicht die

8 Als Äquivalent sowohl zum Niederländischen als auch zur englischen way-Konstruktion wird die reflexive Bewegungskonstruktion auch von van Egmond (2009: 162) erwähnt.

9 Für die reflexive Partikelverbkonstruktion (Abschnitt 3.2) gilt dies analog.

10 Für diesen prototypenbasierten Ansatz, den ich in Abschnitt 5.4 näher erläutere, spricht, dass auch Mortelmans \& Smirnova (2020: 62) für ihre beiden Äquivalente festhalten, dass ,the boundary between them is not always clear.“ 
reflexive Bewegungskonstruktion als primäres Äquivalent zur way-Konstruktion, sondern die formal ähnlichere, aber im Deutschen wesentlich unproduktivere reflexive Weg-Konstruktion (Abschnitt 3.3). ${ }^{11}$ Dies führt dazu, dass McColm (2019: 65) die reflexive Bewegungskonstruktion vollständig aus seiner Untersuchung ausschließt. ${ }^{12}$ Die beiden für das Deutsche als Referenzstudien zu betrachtenden Arbeiten von Oya (1999) und Smirnova (2018) zu dieser Konstruktion bezieht er in seine Diskussion erst gar nicht ein. Einen genau entgegengesetzten Weg schlagen Mortelmans \& Smirnova (2020: 61) ein, die die reflexive Bewegungskonstruktion nicht nur als Äquivalent zur way-Konstruktion betrachten, sondern auch zu deren Pendants im Niederländischen, die sich, wie in meinem Ansatz, in die reflexive Bewegungskonstruktion einerseits und die reflexive Weg-Konstruktion andererseits ausdifferenzieren lassen. Die reflexive Partikelverbkonstruktion berücksichtigen sie nicht.

Hinsichtlich semantischer Ansätze zur Untersuchung der Konstruktion ist festzuhalten, dass eine frame-semantische Analyse - gleich welchen FrameModells - bisher nicht vorliegt. Die bereits im Eingang zu diesem Abschnitt genannten Analysen der way-Konstruktion, die auf den Frame Motion hinweisen, beschränken sich wie vordergründig das FrameNet-Konstruktikon auf diesen globalen Verweis, ohne etwa die Parallelen zwischen den FE des Frames und den Strukturelementen der Konstruktion in den Blick zu nehmen (vgl. Unterabschnitt 2.3.2). Unabhängig davon weist Smirnova (2018: 28) auf ,zwei verbale Szenen bzw. Subevents“ hin, die in der Konstruktion zusammenkommen, ohne dabei jedoch explizit frame-semantisch zu argumentieren. Dasselbe Desiderat lässt sich für die reflexive Partikelverbkonstruktion und die reflexive Weg-Konstruktion festhalten.

Durch die enge Orientierung an der Forschung zur way-Konstruktion besteht die bisherige Beschreibung von Eigenschaften der reflexiven Bewegungskonstruktion vor allem in einem Abgleich mit den Eigenschaften ihres englischen Äquivalents. Gerade die frühen Studien, die noch ohne korpusbasierte Analysen auskommen, verfahren in dieser Art, ohne zu hinterfragen, ob die angenommenen Ge-

11 McColm (2019) verwendet für die Konstruktionen im Englischen, Deutschen und Niederländischen grundsätzlich den Begriff der way-Konstruktion. Um die Unterschiede in den von ihm zumindest erwähnten Konstruktionen kenntlich zu machen, verwende ich die in dieser Arbeit gebrauchten Konstruktionsnamen, wenngleich bei ihm keine Entsprechungen dazu zu finden sind.

12 Als Grund dafür nennt McColm (2019: 172-173) das Problem, dass Kontaminationen zwischen der reflexiven Weg-Konstruktion und der reflexiven Bewegungskonstruktion nicht untersuchbar seien, weil Letztere eine stärker manuelle Datenauswahl erforderlich macht. Obwohl dieses Argument grundsätzlich berechtigt ist (vgl. Unterabschnitt 3.4.1), darf davon nicht auf die pauschal stärkere Äquivalenz der reflexiven Weg-Konstruktion zur way-Konstruktion geschlossen werden. 
meinsamkeiten und Unterschiede einer gebrauchsbasierten Überprüfung standhalten, weshalb ich darauf in Unterabschnitt 3.1.4 eingehen möchte.

\subsubsection{Strukturelemente}

Die reflexive Bewegungskonstruktion verfügt über vier Strukturelemente. In Tabelle 3.1 sind diese mitsamt vorläufiger (überwiegend formaler) Definitionen zusammengefasst. Diese Definitionen sind unter anderem deshalb vorläufig, weil sowohl ihr Zustandekommen als auch die Benennung der Strukturelemente ein wesentlicher Teil konstruktikographischer Arbeit ist und auf genuin konstruktionssemantischer Basis vorgenommen werden muss. Dazu dienen, wie in Abschnitt 7.3 zu sehen sein wird, insbesondere diejenigen Frames, die in den Konstrukten der Konstruktion evoziert werden, sowie ihre FE, die die einzelnen Strukturelemente der Konstrukte semantisch motivieren.

Tab. 3.1: Strukturelemente der reflexiven Bewegungskonstruktion

\begin{tabular}{|c|c|}
\hline Strukturelement & Vorläufige Definition \\
\hline BEWEGENDES & $\begin{array}{l}\text { Die KtE dieses KE referieren auf eine (belebte oder unbelebte) Entität, die } \\
\text { eine ,Bewegung' ausführt. Die Entität muss mit derjenigen, auf die das KEE } \\
\text { referiert, identisch sein. }\end{array}$ \\
\hline EREIGNIS & $\begin{array}{l}\text { Die KtE dieses KE referieren auf ein Ereignis, das als eine ,Bewegung، der } \\
\text { Entität, auf die die KtE des KE BEWEGENDES referieren, verstanden werden } \\
\text { kann oder mit dieser ,Bewegung، einhergeht. }\end{array}$ \\
\hline KEE & $\begin{array}{l}\text { Das KEE wird durch ein Reflexivum (im weitesten Sinne) instanziiert. Da- } \\
\text { bei kann es sich um das, echte‘ Reflexivpronomen sich oder ein reflexiv ge- } \\
\text { brauchtes Personalpronomen in 1. oder } 2 \text {. Person handeln. Handelt es sich } \\
\text { um Letzteres, muss es auf dieselbe Entität wie das KtE des KE BEWEGENDES } \\
\text { referieren. Das Reziprokpronomen einander ist ebenso belegt. }\end{array}$ \\
\hline WEG & $\begin{array}{l}\text { Die KtE dieses KE spezifizieren die räumliche Ausdehnung der ,Bewegung } \\
\text { der Entität, auf die das KtE des KE BEWEGENDES referiert. }\end{array}$ \\
\hline
\end{tabular}

An dieser Stelle lässt sich aber bereits festhalten, dass im Gegensatz zu den im FrameNet-Konstruktikon für die way-Konstruktion inventarisierten Strukturelementen (Tabelle 2.4 in Unterabschnitt 2.3.2) folgende Änderungen vorgenommen werden müssen. 
- Das KE Theme, das bei der way-Konstruktion nach dem FE Motion.Theme benannt ist, ${ }^{13}$ bezeichne ich als BEWEGENDES, weil nicht alle Konstrukte der reflexiven Bewegungskonstruktion eine Instanz des FE Motion.THEME in diesem KE aufweisen. Stattdessen ist die semantische Motivierung der KtE dieses KE von dem durch das KtE des KE EREIGNIS evozierten Frame abhängig. Damit ist jedoch nicht ausgeschlossen, dass das FE Motion.THEME als für die Definition des KE BEWEGENDES prototypisch angesehen werden kann (vgl. Unterabschnitt 7.3.2).

- Die KE MAKE_VERb, INTRANSITIVE_MANNER_VERB bzW. INTRANSITIVE_ MEANS_VERB, TRANSITIVE_MANNER_VERB bZW. TRANSITIVE_MEANS_VERB fasse ich unter dem KE EREIGNIS zusammen, da ich von den formalen Unterschieden (intransitiv/transitiv) absehe und für die konstruktikographische Repräsentation der unterschiedlichen Lesarten eine andere Form wähle (vgl. Abschnitt 5.2 sowie Unterabschnitte 7.1.3 und 7.2.2). ${ }^{14}$ Man beachte indes, dass sich die semantischen Unterschiede der KE im FrameNet-Konstruktikon (,manner'- oder ,means'-Verb) zusätzlich in der Bezeichnung der Lesarten der Konstruktion (way_manner und way_means) widerspiegeln und damit ohnehin redundant sind.

- Die KE Direction, GoAl, PAth und Source fasse ich als KE Weg zusammen, da die korrespondierenden FE von Motion (oder anderen Frames) zu einem Core Set gehören und sie deshalb zu dem, was ich später Makro-FE nenne (Unterabschnitt 7.3.3), generalisiert und auf das entsprechende KE bezogen werden können. ${ }^{15}$

13 Schon bei Goldberg (1995: 207) wird dieses Strukturelement „creator-theme“ genannt.

14 Mit dem Terminus Ereignis ist keine Subkategorisierung der als KtE möglichen LE impliziert, die sich z.B. auf eine semantische Klassifikation in ,Handlungs-', ,Vorgangs-' oder ,Zustandsverben` bzw. -prädikate (z.B. Welke 2005: 168-170; von Polenz 2008: 159-167; Hentschel \& Weydt 2013: 31-32; Ágel 2017: 363-364) berufen würde und für die als Oberbegriff bisweilen der Terminus Ereignis verwendet wird, wie etwa bei Welke (2005: 170), Löbner (2015: 126) oder Ágel (2017: 363-364). Grundsätzlich ist eine solche semantische Bezeichnung jedoch einer formal orientierten und auf die Wortart (Verb) zurückgreifenden wie der des FrameNet-Konstruktikons vorzuziehen, da, wie ich in Unterabschnitt 6.1.2 argumentiere, die Eigenschaften von KE und ihrer KtE primär semantischer Natur sind. Dabei bleibt selbstverständlich zu berücksichtigen, dass die Zuordnung einer LE zu einer semantischen Klasse wie ,Handlungs-‘, ,Vorgangs-` oder ,Zustandsverb` kontextuell determiniert und keineswegs lexikalisch invariant ist (vgl. Hentschel \& Weydt 2013: 32), weshalb Lehmann (2017: 89, Anm. 99) vorschlägt, von Handlungs-, Vorgangs-, oder Zustandsbedeutungen zu sprechen. Wie die Wahl des Terminus Ereignis aus konstruktionssemantischer Sicht zu begründen ist, zeige ich in Unterabschnitt 7.3.1.

15 In dieser Hinsicht folge ich Goldberg (1995: 207), die dieses Strukturelement bereits „path“ nennt (vgl. auch Rohde 2001: 15, 38, 289-294). Dieselbe Bezeichnung nutzt Oya (1999: 360) als 
- Das KE ModIfIER, das Teil des KEE der way-Konstruktion sein kann, entfällt im Deutschen, da die englische way-NP, die das KEE konstituiert, in der reflexiven Bewegungskonstruktion keine Entsprechung findet. Anders ist dies allerdings für die reflexive Weg-Konstruktion, weshalb für sie ein mit der englischen way-NP korrespondierendes KorE angesetzt wird, das potenziell ebenfalls eine (in meinen Korpusdaten aber nicht belegte) Modifikation erlaubt (vgl. Unterabschnitt 3.3.2).

- Die KE MANNER und MEANS, die den FE Motion.〈MANNER〉 und Motion.〈MEANS〉 entsprechen, sehe ich nicht als ausschließliche Eigenschaften der Konstruktion an, da viele Frames, insbesondere jene, die in einer Frame-zu-FrameRelation zu Motion stehen, diese ebenfalls beinhalten. ${ }^{16}$

Eine Annotation der vier Strukturelemente der reflexiven Bewegungskonstruktion (Tabelle 3.1) kann für die Belege (1)-(10) wie in (11)-(20) dargestellt werden.

(11) Seitdem $\left\{\right.$ [EReignis $_{\text {arbeitet] [KeE }}$ sich] [Bewegendes der Professor] acht Monate im Jahr mit einem Jeep [WEG durch die Wüste von Turkmenistan]\}, harrt in Kasachstan stundenlang in ungeheizten Sitzungszimmern aus und bewahrt in Usbekistan auch nach dem sechsten Wodka noch die Contenance. (Die Zeit, 24.02.2000, Nr. 9)

(12) Der Fabrikant breitete sein Schweigen wieder aus, $\{$ [Bewegendes $\operatorname{der}$ Offizier] [EREIGNis mogelte] [KEE sich] [WEg aus seinem Sitz]\}. (Düffel, John von: Vom Wasser, München: dtv 2006, S. 56)

(13) $\{$ [Bewegendes Mancher Programmdirektor] [EREIgnis wünscht] [KEe sich] hier inzwischen [WEG auf eine wirklich einsame Insel]\}. (Die Zeit, 30.03.2000, Nr. 14)

(14) Marie saß seit dem späten Nachmittag an ihrem kleinen Schreibtisch in ihrem Zimmer und \{[EREIGNIs kämpfte] [KEE $\mathrm{sich}$ ] [WEG durch Theodor Fontanes Der Stechlin]\}, über den sie eine Arbeit schreiben mußte. (Suter, Martin: Lila, Lila, Zürich: Diogenes 2004, S. 47)

\footnotetext{
„Oberbegriff für SOURCE/PATH/GOAL“. Entsprechend geht auch - allerdings nicht auf diese Konstruktion bezogen - Ungerer (2017: 4) vor.

16 Die von Müller (2007: 192-193) am Beispiel von Resultativkonstruktionen problematisierte Frage, inwiefern solche traditionell als Adjunkte verstandenen Elemente auf Ebene der Konstruktion angenommen werden müssen, lässt sich damit allerdings noch nicht vollständig beantworten. Die Tatsache, dass sie bereits als FE in zahlreichen lexikalischen Frames (zu diesem Begriff vgl. Abschnitt 4.2) enthalten sind, rechtfertigt aber zunächst, für sie keine eigenen KE anzunehmen.
} 
(15) Als ich Tina kennenlernte, gingen wir zwar ein- oder zweimal zu viert essen, aber die Gespräche kamen nicht in Gang, \{[Bewegendes man] [EReIgnis quälte] [KEE sich] [WEG durch typische Konversationsthemen wie Tagespolitik, neue Bücher, alte Gemälde und schlechtes oder gutes Wetter und die Auswirkungen all dessen auf die Gelenke]\}. (Goosen, Frank: Liegen lernen, Frankfurt am Main: Eichborn AG 2000, S. 238)

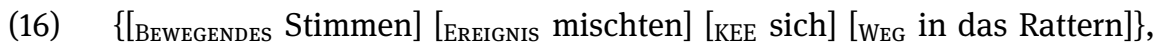
Worte, Sätze, die sie nicht verstand, weil ihr Kopf so verschwommen war. (Pressler, Mirjam: Malka Mai, Weinheim Basel: Beltz \& Gelberg 2001, S. 248)

(17) Die Babylonier nickten und \{[EREIGNIs quetschten] [KEE sich] ungelenk [WeG durch die Glastür auf die Steinstraße]\}. (Kopetzky, Steffen: Grand Tour, Frankfurt am Main: Eichborn 2002, S. 283)

(18) Ich arbeitete gut und konzentriert; ich hatte Kräfte für zehn - und doch schlugen mir die Knie aneinander, als ich in die Allee einbog, und $\{[$ BEWEGENDEs meine Hände] [EREIGNis gruben] [KEE sich] [WEG in die Rocktaschen]\}, bis sie beinahe rissen. (Schmitter, Elke: Frau Sartoris, Berlin: BvT 2000[2002], S. 29)

(19) $\{$ [Bewegendes Mommsen] [Ereignis rettete] [KeE sich] [Weg aus der Welt der Tatsachen] in die der Gefühle\}: (de Bruyn, Günter: Preußens Luise, Siedler 2001, S. 87)

(20) Es war allen Anwesenden nachzufühlen; von unschuldigem Frohsinn war nichts zu spüren, die Abende zogen sich dahin, der Steuereintreiber und der Chirurg entschuldigten sich schon früh, um nicht wieder in den Genuß von Gratiskonsultationen zu kommen, der Priester gab seine zwei Witze zum besten, und der Rest lästerte über das Essen und \{[EREIGNis soff] [KEE sich] [WeG unter den Tisch]\}, weil selbst die Konjunktur als Thema längst ausgeschöpft war. (Schrott, Raoul: Tristan da Cunha oder die Hälfte der Erde; Hanser Verlag 2003, S. 196)

Der auffälligste formale Unterschied der reflexiven Bewegungskonstruktion im Vergleich zur way-Konstruktion besteht darin, dass die NP aus Possessivpronomen und dem Nomen way, die der englischen Konstruktion ihren Namen gibt und als ihr KEE dient (vgl. etwa Lee-Goldman \& Petruck 2018: 26), in der reflexiven Bewegungskonstruktion nicht existiert und diese stattdessen ein Reflexivum auf- 
weist, ${ }^{17}$ das analog als KEE angesetzt werden kann. ${ }^{18}$ Hierbei weiche ich insofern von der strengen Auffassung eines KEE als (über alle Konstrukte hinweg invariant) „lexically specified CE“ (Ziem \& Flick 2019: 204; Ziem, Flick \& Sandkühler 2019: 68) ab, da sich an dieser Position nicht nur das ,echte' Reflexivum sich auffinden lässt, sondern ebenso eine Reihe funktional identischer Personalpronomen (vgl. Eisenberg 2013: 172-173; Hentschel \& Weydt 2013: 224-225; Duden 2016: 271), die über eine „Persondeixis in reflexiver oder reziproker Lesart“ (Zifonun, Hoffmann \& Strecker 1997: 1355) verfügen. In seltenen Fällen tritt auch das Reziprokpronomen einander auf. ${ }^{19}$ Einziges notwendiges Kriterium ist, dass das Pronomen einen „Rückbezug auf das Denotat einer anderen primären Komponente“ (Zifonun, Hoffmann \& Strecker 1997: 1357) aufweist, also mit den KtE eines anderen KE - hier: des KE BEWEGENDES - referenzidentisch ist. ${ }^{20}$ Neben dem ,echten' Reflexivpronomen sich in 3. Person finden sich vor allem für das reflexiv gebrauchte Personalpronomen mich, also für die 1. Person Singular, einige Belege, wie (21)-(23) zeigen.

17 Eine analoge Struktur mit dem Nomen Weg lässt sich im Deutschen und z.B. auch im Niederländischen in Gestalt der reflexiven Weg-Konstruktion (Abschnitt 3.3) finden, sie ist allerdings auf wenige LE beschränkt und mit den angenommenen semantischen Eigenschaften nicht produktiv (vgl. Smirnova 2018: 22-25; Mortelmans \& Smirnova 2020: 59-60).

18 Ein Argument, schon die englische NP aus Possessivpronomen und dem Nomen way als KEE anzusetzen ist, dass die Konstruktion ,partially lexically filled (by the noun way)“(Goldberg 1996: 29) ist. Ebenso listen Goldberg \& Jackendoff (2004: 533) die way-Konstruktion unter ,constructions in which a standard syntactic position is occupied by a special element that marks the construction."

19 Nach dem Vorbild von Hentschel \& Weydt (2013: 224-225) und Lehmann (2017: 17) verwende ich den Begriff Reflexivum statt des Begriffs Reflexivpronomen. Damit soll insbesondere deutlich werden, dass es nicht in jedem Auftreten wie andere Pronomen referenziell verwendet werden muss (vgl. dazu Kunze 1997: 88; Zifonun 2003: 68-69; Ágel 1997b: 71, 2017: 334-335). Somit dient der Begriff Reflexivum als Sammelbegriff für alle Varianten des KEE, neben dem ,echten' Reflexivpronomen sich also insbesondere auch für ,reflexiv gebrauchte[] Personalpronomen“ (Duden 2016: 271) in der 1. und 2. Person (mich, dich, uns, euch). Einzige Ausnahme ist das davon abzugrenzende Reziprokpronomen einander. Ferner folge ich im Erlauben von Varianten des KEE Langacker (2000: 11), der Abweichungen kleinerer Eigenschaften eines Schemas von Gebrauchsereignis zu Gebrauchsereignis (hier also: von Konstrukt zu Konstrukt) als irrelevant für die Konventionalisierung dieses Schemas ansieht.

20 Auf ein ähnliches Kriterium weist Goldberg (2014: 121) für die way-Konstruktion hin und betont damit die syntagmatischen Zusammenhänge zwischen den Strukturelementen der Konstruktion. Die angesprochene Referenzidentität lässt sich jedoch nicht für alle Reflexivkonstruktionen beobachten und ist deshalb nicht verallgemeinerungsfähig, sondern nur konstruktionsspezifisch aufzufassen (vgl. dazu problematisierend Lehmann 2017: 74). Für die reflexive Bewegungskonstruktion nehme ich allerdings an, dass sie gegeben ist. 
(21) Abends las ich, die Bücherei war ziemlich umfangreich, und fich fraß [KEE mich] durch alles\}; langsam, genügsam, manchmal mit wirklicher Anteilnahme. (Schmitter, Elke: Frau Sartoris, Berlin: BvT 2000[2002], S. 35)

(22) „Welche Landschaft?“ frage ich, \{schäle [KEE mich] vorsichtig aus der Decke\} und schaue mich um. (Riedel, Susanne: Eine Frau aus Amerika, Berlin: Berlin Verlag 2003, S. 74)

(23) \{Ich kämpfte [KEE mich] durch dieses Unterholz\}, hielt mich an den Stämmen, Asten und Wurzeln fest, weil ich hinauf zum Gipfel wollte, der wie jeden Tag in den Wolken lag; wie dick die Schicht war, ließ sich nicht sagen - vielleicht schien oben die Sonne. (Schrott, Raoul: Tristan da Cunha oder die Hälfte der Erde; Hanser Verlag 2003, S. 161)

Das Reziprokpronomen einander ist nur selten belegt, etwa in (24). ${ }^{21}$

(24) Es war ein wüster Abend, bei dem viel geschrien und grell gelacht wurde; \{die Darsteller jagten [KEE einander] über die Bühne\}, es knallte an allen Ecken und Enden, so daß man den Text kaum verstand. (Schmitter, Elke: Frau Sartoris, Berlin: BvT 2000[2002], S. 87)

Diese Feststellungen können Anlass zur Überlegung geben, ob man für unterschiedliche, aber verwandte KEE nicht separate Konstruktionen ansetzen müsste, die zu einer Konstruktionsfamilie (im Sinne von Goldberg \& Jackendoff 2004: 535536) gehören. Für die reflexive Bewegungskonstruktion gehe ich davon nicht aus, da ich die semantischen Unterschiede zwischen den einzelnen Reflexiva als zu gering erachte, als dass sie die Annahme distinktiver Konstruktionen rechtfertigen würden. ${ }^{22}$ Vielmehr handelt es sich bei Konstrukten mit unterschiedlichen

21 Kunze (1995: 22) allerdings bestreitet, ohne gebrauchsbasierte Evidenz, ein Auftreten des Reziprokpronomens einander in der reflexiven Bewegungskonstruktion. Diese Annahme kann also widerlegt werden.

22 Zwei Beispiele für eine Trennung von Konstruktionen und ihren konstruktikographischen Einträgen sind Exklamativ- und Negationskonstruktionen. Im Konstruktikon des Deutschen etwa werden die Konstruktionen beider Konstruktionsfamilien nach ihren KEE getrennt, bei Exklamativa etwa nach KEE wie Allein (https://gsw.phil.hhu.de/constructiconold/construction?id=20, zuletzt abgerufen am 07.09.2021), So (https://gsw.phil.hhu.de/constructiconold/construction?id= 22, zuletzt abgerufen am 07.09.2021) oder Was für (https://gsw.phil.hhu.de/constructiconold/ construction?id=13, zuletzt abgerufen am 07.09.2021), bei Negationskonstruktionen etwa nach KEE wie Und erst recht nicht (https://gsw.phil.hhu.de/constructiconold/construction?id= 4, zuletzt abgerufen am 07.09.2021), Weder noch (https://gsw.phil.hhu.de/constructiconold/ construction?id=12, zuletzt abgerufen am 07.09.2021) oder geschweige denn (https://gsw.phil.hhu. de/constructiconold/construction?id=10, zuletzt abgerufen am 07.09.2021). 
Reflexiva als KEE um Allokonstrukte, ,denen trotz ihrer Distinktivität mit hoher Plausibilität eine gemeinsame Konstruktion in der Kompetenz zugeordnet werden kann.“ (Bücker 2014: 131). ${ }^{23}$

\subsubsection{Konstruktionelle Polysemie}

Wenngleich die way-Konstruktion und die reflexive Bewegungskonstruktion einige formale Unterschiede trennen, sind sie durch eine semantische Gemeinsamkeit verbunden, die über die Zuschreibung von Motion als zentrale Komponente ihrer semantischen Eigenschaften hinausgeht. Es handelt sich um ihre konstruktionelle Polysemie: Beide subsumieren unterschiedliche Lesarten ihrer Konstrukte. Im FrameNet-Konstruktikon werden, wie bereits in Unterabschnitt 2.3.2 angesprochen, drei Lesarten festgehalten und in drei Konstruktionseinträgen getrennt dokumentiert: ,way_neutral', ,way_manner' und ,way_means'.

Diese Praxis ist ein Reflex der frühesten Forschung zur way-Konstruktion, werden doch seit Levin \& Rapoport (1988: 278) und Jackendoff (1990: 216) zwei Lesarten angesetzt, die spätestens seit Goldberg (1995: 202) als ,manner'- und ,means'Lesart bezeichnet werden. ${ }^{24}$ In ihren diachronen Studien zur way-Konstruktion legen Israel (1996: 218) und Perek (2018: 68-69) noch eine dritte Lesart zugrunde: Neben der ,manner'- und der ,means'-Lesart wird dort noch eine, incidental activity'-Lesart angesetzt (im Folgenden kurz, incidental'), die diejenigen Fälle erfasst, in denen das vom Verb (einem KtE des KE EREIGNIS) ausgedrückte Ereignis und die von der Konstruktion hinzugefügte semantische Komponente der ,Bewegung (der auf Motion zurückgeht) in keinerlei logischem Zusammenhang stehen. ${ }^{25}$ McColm (2019: 39) nimmt an, dass diese drei Lesarten auch auf das deutsche Äquivalent der way-Konstruktion zutreffen. Nimmt man die im FrameNet-

23 Als Alternative zum Begriff des Allokonstrukts lässt sich die von Bücker (2012: 5) an anderer Stelle eingeführte Unterscheidung von „Basiseigenschaften und variierenden Eigenschaften“ einer Konstruktion verstehen. $\mathrm{Zu}$ den Basiseigenschaften der reflexiven Bewegungskonstruktion zählt dann etwa, dass das KEE aus einem Reflexivum bestehen muss, während die konkrete morphologische Gestalt dieses Reflexivums zu den variierenden Eigenschaften der Konstruktion zählt. Das KEE wird damit lediglich kategorial und nicht im strengen Sinne als morphologisch fixiert definiert.

24 Smirnova (2018: 21) übersetzt die beiden Lesarten mit ,modal' (,manner') und ,instrumental ${ }^{\star}$ $\left(\right.$,means $\left.{ }^{`}\right)$. Aufgrund der im internationalen Raum verbreiteteren englischen Begriffe behalte ich diese jedoch bei.

25 Auch für die ,incidental'-Lesart behalte ich den englischen Terminus bei, da die plausibelste deutsche Übersetzung als ,Unverbundenheit' der beiden semantischen Komponenten zu falschen Suggestionen hinsichtlich meines Konzepts der Frame-Nähe (Abschnitt 5.4) führen würde, in dem es gerade um die ,Verbundenheit‘ zweier Frames geht. Ihre ,Unverbundenheit‘ kor- 
Konstruktikon dokumentierte neutrale Lesart hinzu, ergeben sich also insgesamt vier Lesarten, die die Polysemie der Konstruktion konstituieren. Bevor ich sie in Abschnitt 5.2 eingehender untersuche und konstruktionssemantische Vorschläge zu ihrer Differenzierung unterbreite, seien sie im Folgenden durch einige Belege illustriert.

Die neutrale Lesart liegt vor, wenn die als KtE des KE EREIGNIS instanziierte LE in ihrer lexikalischen Bedeutung weder hinsichtlich eines ,manner'-, noch hinsichtlich eines ,means'-Aspekts spezifiziert ist (etwa in den gleichnamigen FE des von ihr evoziertes Frames) ${ }^{26}$ und auch kein weiterer Frame hinzutritt, sodass sich auch keine ,incidental'-Lesart ergeben kann. Wie die Belege in (25) zeigen, trifft dies auf bestimmte LE zu, die Motion evozieren, etwa bewegen (move.v) oder begeben (go.v) - hier und im Folgenden als KtE des KE EREIGNIS annotiert.

a. Langsam $\{$ [EREIGnis bewegte] sich das Skelett durch das Gras\}. (Glavinic, Thomas: Die Arbeit der Nacht, München Wien: Carl Hanser Verlag 2006, S. 134)

b. \{Keiner [EREIGNis begibt] sich in die holzhüttenartige Kabine\}. (Düffel, John von: Vom Wasser, München: dtv 2006, S. 192)

Doch auch andere Frames und die sie evozierenden LE kommen für die neutrale Lesart infrage, so etwa Body_movement in den Belegen in (26) mit LE wie hängen (hang.v), biegen (bend.v) oder beugen (flex.v).

(26) a. \{Bob und Neill [EREIGNIs hängen] sich aus den heruntergekurbelten Fenstern\} und winken den Mädchen so lange nach, bis der Wagen abbiegt. (Dölling, Beate: Hör auf zu trommeln, Herz, Weinheim: Beltz \& Gelberg 2003, S. 84)

b. Bei der Erinnerung daran verlor Alexander die Fassung, schluchzte und $\{[$ EReignis bog] sich tief in seinen Sessel zurück\}. (Krausser, Helmut: Eros, Köln: DuMont 2006, S. 239)

c. \{Der ehemalige italienische Ministerpräsident Giuliano Amato [EREIGNIS beugte] sich mit einer Arbeitsgruppe über Die Natur der Neuen Grenze\} und zog energisch den Schluss, dass es ohne Grenzen nicht gehe. (Die Zeit, 20.01.2000, Nr. 4)

reliert aber gerade nicht (zwingend) mit der ,incidental'-Lesart. Auch der von Fanego (2019: 693) vorgeschlagene Terminus „,co-occurrence relation“ eignet sich aufgrund seiner anderweitigen linguistischen Konnotation nicht zur Bezeichnung dieser Lesart.

26 Zur Unterscheidung zwischen Frame und lexikalischer Bedeutung vgl. Unterabschnitt 4.1.1. 
Für die ,manner'-Lesart kommt nun im Gegensatz zur neutralen Lesart hinzu, dass die lexikalische Bedeutung der LE, die als KtE des KE EREIGNIs instanziiert wird, durch einen ,manner'-Aspekt spezifiziert sein muss. Die Belege in (27) zeigen, dass dies für bestimmte andere LE, die Motion evozieren, zutrifft, so etwa schlängeln (snake.v) oder mäandern (meander.v). Auch bestimmte LE, die Self_motion evozieren, kommen dafür infrage, etwa robben (crawl.v), pressen (press.v) oder stehlen (steal.v) in (28).

(27) a. \{Ich [EREIGNIS schlängelte] mich durch die Autos und die Abgase, die rot zwischen den Schlußlichtern dampften\}, und entdeckte gerade noch rechtzeitig die kräftige Gestalt von John Bird hinter dem erleuchteten Schaufenster. (Franck, Julia: Lagerfeuer, Köln: DuMont Literatur und Kunst Verlag 2003, S. 256)

b. \{So [EREIGNIs mäandern] sich die nackten und verschlungenen Leiber durch die Werbung und über die Titel jener der Werbeästhetik folgenden Magazine\}. (Die Zeit, 13.01.2000, Nr. 3)

(28) a. General Motors geht es mit seiner Tochter Opel kaum besser, \{Fiat [EREIGNis robbt] sich mühsam aus den roten Zahlen\}, und Renault hat die Übernahme von Nissan noch längst nicht bewältigt. (Die Zeit, 24.02.2000, Nr. 9)

b. \{Sie [EReignis presste] sich unter den Zweigen auf den Boden\}. (Boie, Kirsten: Skogland, Ort: Hamburg 2005, S. 343)

c. \{Die Morgensonne [EReIgnis stahl] sich schon durch die Ritzen der Fensterläden\}, aber in dem großen Haus war es so still, als schliefen selbst die Bücher in den Regalen. (Funke, Cornelia: Tintenherz, Hamburg: Cecilie Dressler Verlag 2003, S. 94)

Die Differenzierung zwischen neutraler und ,manner'-Lesart ist somit zu großen Teilen abhängig von der lexikalischen Bedeutung der LE, die als KtE des KE EREIGNIS instanziiert wird (vgl. Unterabschnitt 5.2.3). Auch die ,means'- und ,incidental'-Lesarten lassen sich auf Frames zurückführen, die von jenen KtE evoziert werden. So ist das Konstrukt in (29) nur so zu interpretieren, dass der weiße Fleck sich nur durch das ,Mittel‘ des Ereignisses des ,Fressens‘, das der von der LE fressen (etwa: eat.v) evozierte Frame Ingestion anzeigt, in die Umgebung ,bewegen'kann.

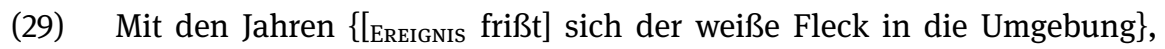
verschwinden Sehenswürdigkeiten und Aussichtspunkte, ein Dorf, eine Stadt, alles nur eine Frage des Maßstabs. (Schulze, Ingo: Neue Leben, Berlin: Berlin Verlag 2005, S. 195) 
Ähnlich ist es in (30): Die ,Bewegung‘ des Vaters ist nur aufgrund des Ereignisses des ,Schlagens“ möglich, die LE schlagen evoziert in diesem Fall den Frame Impact.

(30) [Der Vater [EREIGnis schlug] sich durch die Haus- und Gartentür, die danach, und für Jahre, schräg in den Angeln hing\}. (Widmer, Urs: Das Buch des Vaters, Zürich: Diogenes 2004, S. 153)

Exakte Kriterien, wie die ,incidental'-Lesart von der ,means'-Lesart abgegrenzt werden kann, finden sich in der bisherigen Forschung zur way-Konstruktion nicht. Hinsichtlich der ,incidental'-Lesart hält allerdings Perek (2018: 86-87) fest, dass sie insbesondere mit Verben der ,Nahrungsaufnahme‘ (z.B. essen, trinken), der ,Darbietung' (z.B. tanzen, spielen, singen), Körperfunktionen (z.B. husten, niesen, schwitzen), ,Geräuschemissionen‘ (z.B. knallen, knirschen, trommeln), ,Kommunikation' (z.B. entschuldigen, scherzen, reden), ,Weinen' (z.B. heulen, schreien, quieken) und anderen menschlichen ,Geräuschemissionen' (z.B. keuchen, grunzen, seufzen) auftritt (vgl. auch McColm 2019: 21-22). Wie ich in Unterabschnitt 5.2.3 ausführlicher zeigen werde, ist dieses Kriterium der Verbklassifizierung allerdings zu grobkörnig, um zwischen den Lesarten zu unterscheiden. Ohne zu sehr auf die dortigen Analysen vorzugreifen, sei an (31)-(35) illustriert, dass das durch LE wie trauen (dare.v) mit dem Frame Daring (31), leben (live.v) mit Dead_or_alive (32), reden (talk.v) mit Chatting (33), heulen (cry.v) mit Make_noi se (34) oder jagen (hunt.v) mit Hunting (35) markierte Ereignis in keinem kausalen oder anderweitigen Zusammenhang zu den auf Motion basierenden semantischen Eigenschaften der Konstruktion stehen muss.

(31) \{Ich [EREIgnis traute] mich kaum an sie heran\}. (Goosen, Frank: Liegen lernen, Frankfurt am Main: Eichborn AG 2000, S. 295)

(32) \{Man [EREIGNis lebte] sich aus der herausgerissenen Zeit, in der man saß, zurück in die Erinnerung ans Zuhause von damals und voraus in die Hoffnung, bald heimzukehren\}. (Müller, Herta: Der König verneigt sich und tötet, München: Carl Hanser Verlag 2003, S. 42)

(33) Dann ist er an der Reihe, beginnt bedächtig und \{[EREIGNis redet $]$ sich in eine Leidenschaft, neben der Angela Merkel blutleer wirkt\}. (Die Zeit, 16.03.2000, Nr. 12)

(34) „... für die vielen Toten und Verwundeten hergeschickt worden waren, nachgerückt wie Kegel im Spiel“, machte der Vater seinen Fehler wieder gut, „\{junge Kerle, gerade Abitur gemacht, [EREIGNIs heulten] sich auf ihren Strohschütten in den Erdbunkern, wo wir uns zusammendrängten, in 
den Schlaf\}. (Hahn, Ulla: Unscharfe Bilder, München: Deutsche VerlagsAnstalt 2003, S. 103)

(35) Es war ein wüster Abend, bei dem viel geschrien und grell gelacht wurde; \{die Darsteller [EREIGnis jagten] einander über die Bühne\}, es knallte an allen Ecken und Enden, so daß man den Text kaum verstand. (Schmitter, Elke: Frau Sartoris, Berlin: BvT 2000[2002], S. 87)

Wie die Differenzierung der Lesarten untereinander, so ist auch ihre generelle Existenz nicht unumstritten. Während die neuere Forschung, etwa McColm (2019: 39), wie bereits erwähnt, davon ausgeht, dass alle für die englische way-Konstruktion feststellbaren Lesarten auch im Deutschen existieren, gehen Kunze (1995: 25) und Oya (1999: 362-363) - ohne gebrauchsbasierte Evidenz - davon aus, dass die ,manner'-Lesart im Deutschen nicht vorhanden wäre. Dieser Befund lässt sich allerdings korpusbasiert leicht widerlegen, wie die Belege in (27) und (28) zeigen. Auf einen grundsätzlich problematischen Aspekt der Unterscheidung weist indes Goldberg (1995: 202-203) hin, wenn sie bemerkt, dass viele Konstrukte der ,manner'-Lesart ebenso als ,means'-Lesart interpretiert werden können. Eine empirische Analyse stößt hier auf das Problem, eine Entscheidungsbasis für die Differenzierung der beiden Lesarten zu finden. So ist im Falle der konstruktikographischen Erfassung der drei Lesarten im FrameNet-Konstruktikon etwa unklar, nach welchen Kriterien ,manner'-Verben von ,means'-Verben unterschieden werden, um sie als KtE unterschiedlicher KE, z.B. INTRANSITIVE_MANNER_VERB oder TRANSITIVE_MEANS_VERB, zu annotieren.

Für die deutsche Konstruktion weist bereits Maienborn (1994: 242-243) darauf hin, dass Entscheidungen über ihre Lesarten nur durch umfangreiches Hintergrundwissen und Kenntnisse über Kontexte zu treffen sind. In diesem Sinne konstatiert auch Smirnova (2018: 36-37), dass unterschiedliche Lesarten der Konstruktion nur in größeren Kontexten differenziert werden können. Ich schließe mich dieser Kritik grundsätzlich an, halte aber gleichzeitig die Praxis der Differenzierung unterschiedlicher Lesarten der Konstruktion, wie sie in der Forschung und der Konstruktikographie betrieben wird, für eine folgerichtige Entscheidung, da hier eine wesentliche semantische Eigenschaft der Konstruktion zu Tage tritt: ihre Polysemie. Fälle solcher konstruktioneller Polysemie müssen Gegenstand konstruktikographischer Auseinandersetzungen mit einer Konstruktion sein, weshalb ich auf sie als Gegenstand eines semantischen Parameters von Konstruktionen in Abschnitt 5.2 zurückkomme. Die Frage nach der konstruktionssemantischen Differenzierung unterschiedlicher Lesarten einer Konstruktion, wie ich sie am Beispiel der way-Konstruktion bzw. der reflexiven Bewegungskonstruktion angedeutet habe, stellt eine zusätzliche Aufgabe (nicht nur) für die konstruktikographische Arbeit dar. 
Mit zu diesen Überlegungen gehört die konstruktikographisch relevante Frage, ob bei Vorliegen mehrerer Lesarten der Konstruktion unterschiedliche Konstruktionseinträge angenommen werden müssen, wie es das FrameNet-Konstruktikon für die way-Konstruktion vorsieht (vgl. Unterabschnitt 2.3.2), oder ob die Lesarten in einem Konstruktionseintrag zusammengefasst werden können (dazu Unterabschnitt 7.2.2). Auch diese Frage ist eine Motivation für die Annahme eines semantischen Parameters von Konstruktionen, der sich ihrer Polysemie widmet.

\subsubsection{Semantische Beschränkungen}

Die konstruktionelle Polysemie der reflexiven Bewegungskonstruktion ist in der bisherigen Forschung nicht der einzige, schon für die way-Konstruktion diskutierte semantische Aspekt, der sie auszeichnet. Einen fast ebenso zentralen Stellenwert nehmen semantische Beschränkungen der way-Konstruktion ein, denen sich auch eine konstruktionssemantische Analyse der reflexiven Bewegungskonstruktion stellen muss. Zwei sehr wesentliche Aspekte lassen sich in den folgenden Punkten paraphrasieren und gelten, wie Kunze (1995: 22), Oya (1999: 357-358) und Smirnova (2018: 34) feststellen, ebenso für das Deutsche. ${ }^{27}$

- Die Konstruktion impliziert eine physische oder (häufiger) metaphorische ,Bewegung' des Referenzobjekts, auf das die KtE des KE BEWEGENDES referieren, und die durch die KtE des KE WEG näher spezifiziert wird, auch und vor allem wenn diese ,Bewegung، der lexikalischen Bedeutung der LE, die als KtE des KE EREIGNIS instanziiert wird, nicht inhärent ist (vgl. Goldberg 1995: 199).

- Diese ,Bewegung، geht oft mit ,Schwierigkeiten“ oder ,Hindernissen“ einher: Der durch die KtE des KE WEG spezifizierte ,Weg‘, auf dem die ,Bewegung“ des Referenzobjekts eines KtE des KE BEWEGENDES stattfindet, muss deshalb von diesem selbst kreiert werden (vgl. Goldberg 1995: 203-204, 1996: 38). Es kann sich dabei um „eine mühsame und langsame Vorwärtsbewegung entlang eines Pfades“ (Smirnova 2018: 36) handeln.

Der erste dieser beiden Punkte verweist auf das Koerzionspotenzial der Konstruktion, die in der Lage ist, den lexikalischen Bedeutungen der LE, mit denen das KE EREIGNIS instanziiert werden kann und in deren lexikalischer Bedeutung keine ,Bewegung، angelegt ist, in der Bedeutung des Konstrukts eine entsprechende semantische Komponente hinzuzufügen. Ich komme auf letzteren Aspekt in Ab-

27 Für den Bezug auf die Strukturelemente der Konstruktion verwende ich die in Unterabschnitt 3.1.2 eingeführten Bezeichnungen, wenngleich diese freilich nicht in der wiedergegebenen Forschungsdiskussion auftreten. 
schnitt 4.4 sowie auf das Koerzionspotenzial als Gegenstand eines semantischen Parameters von Konstruktionen in Abschnitt 5.5 zurück. ${ }^{28}$

Der zweite Punkt rekurriert auf eine semantische Eigenschaft, die auf den ersten Blick auf der Grundlage einer frame-semantischen und konstruktikographischen Annotation schwer zu erfassen ist, da sie nicht unmittelbar an die Strukturelemente der Konstruktion und deren semantische Motivierung durch Frames gebunden zu sein scheint. Wie bereits die Unterscheidung der Lesarten der Konstruktion (Unterabschnitt 3.1.3) stellt somit auch diese semantische Eigenschaft eine konstruktikographische Analyse vor eine konstruktionssemantische Herausforderung. Einen Vorschlag, wie dieser Herausforderung zu begegnen ist, möchte ich im Rückgriff auf die Theorie der konzeptuellen Integration von Fauconnier \& Turner (1998a,b, 2002) mit deren Begriff der emergenten Struktur als Gegenstand eines weiteren semantischen Parameters von Konstruktionen in Abschnitt 5.7 unterbreiten.

Die frühe Forschung, sowohl zur way-Konstruktion als auch zur reflexiven Bewegungskonstruktion, hat über die beiden soeben diskutierten Punkte hinaus noch einige weitere semantische Beschränkungen der einzelnen KE formuliert vor allem, aber nicht nur, hinsichtlich der für das KE EREIGNIS als KtE möglichen Verben -, die teilweise (für die Punkte b und c) auch für ihr deutsches Pendant postuliert werden (vgl. für die way-Konstruktion Goldberg 1995: 212-214, 1996: 44-46; für die reflexive Bewegungskonstruktion Oya 1999: 357-358).

a) Das Verb (hier: das KtE des KE EREIGNIS) muss ein ,iteratives‘ oder ,ungebundenes‘ Ereignis kodieren (vgl. schon Jackendoff 1990: 213; ebenso Jackendoff 1997: 546).

b) Die ,Bewegung' muss (zumindest in der ,means'-Lesart) vom Subjektreferenzobjekt (hier: demjenigen des KtE des KE BEwEGENDES) selbst ausgehen und damit „eine Aktivität darstellen“ (Oya 1999: 357).

c) Die ,Bewegung“ muss „zielgerichtet sein“ (Oya 1999: 358).29

Diese introspektiv gewonnenen und nicht gebrauchsbasiert überprüften Eigenschaften halte ich im Einklang mit zahlreichen neueren Studien für fraglich, da

28 Grundsätzlich unberücksichtigt lasse ich die erwähnte Metaphorik vieler Konstrukte der reflexiven Bewegungskonstruktion, da diese eine separate Analyseebene erfordern würde. Konkret würde dies auf der lexikalischen Ebene eine doppelte Annotation erfordern, wenn man dem Vorschlag von Burchardt et al. (2009: 216) sowie Rehbein et al. (2012: 95-96) folgt, für Quell- und Zieldomäne einer konzeptuellen Metapher (im Sinne von Lakoff \& Johnson 1980) jeweils einen eigenen Frame anzusetzen.

29 Dagegen argumentiert Christie (2011: 4), dass die way-Konstruktion durchaus sowohl telische als auch atelische Handlungen ausdrücken kann. 
sie sich empirisch leicht widerlegen lassen (vgl. für die way-Konstruktion bereits Luzondo Oyón 2013; Szcześniak 2013: 163-167, 2014b: 159-161; Hilpert 2019: 38). Dass die unter a genannte Beschränkung für das Deutsche nicht gilt, zeigt sich an Belegen, in denen die als KtE des KE EREIGNIS instanziierte LE gerade ein singuläres Ereignis kodiert, etwa in dem bereits zitierten Beleg mit der LE retten (rescue.v) in (36), die den Frame Rescuing evoziert.

(36) \{Mommsen [EReignis rettete] sich aus der Welt der Tatsachen in die der Gefühle\}: (de Bruyn, Günter: Preußens Luise, Siedler 2001, S. 87)

Beschränkung b lässt sich mit einer LE wie ergießen (flow.v) in (37) widerlegen, die den Frame Fluidic_motion evoziert.

Wurden die Schleusen des Abzugsgrabens geöffnet und die Wehre der Orpe heruntergelassen, so floß das Orpewasser ab, \{[EREIGNIS ergoß] sich in die Diemel\}, und die Gründe des Harkemanns lagen bloß. (Düffel, John von: Vom Wasser, München: dtv 2006, S. 62)

Wie Luzondo Oyón (2013: 353-354) zeigt, ist die Beschränkung der ,selbstinitiierten Bewegung، grundsätzlich durch Konstrukte widerlegbar, in denen die ,Bewegung، von einer unbelebten Entität ausgeht. ${ }^{30}$ Solche sind zahlreich für die reflexive Bewegungskonstruktion belegt, wie die Beispiele in (38) zeigen.
a. $\{$ [BewegEndes Eine Ahnung von Licht $]$ quält sich durch ein briefbogen- großes, verdrecktes Fenster\}. (Die Zeit, 24.02.2000, Nr. 9)
b. $\{$ [Bewegendes Der Markt] drängt sich in alle Lebenswelten\}. (Die Zeit, 02.03.2000, Nr. 10)
c. \{[Bewegendes Lichtgarben und Wolkenschatten] mengen sich in den Strom, der in seiner Meeresgrüne schäumend aufblitzt\}. (Düffel, John von: Vom Wasser, München: dtv 2006, S. 69)

Für Beschränkung c schließlich stufen Goldberg (1995: 214) und Jackendoff (1997: 546) Konstrukte mit der LE mäandern explizit als (nahezu) inakzeptabel ein. Für die reflexive Bewegungskonstruktion sind sie allerdings durchaus belegt, wie Beleg (39) zeigt.

\footnotetext{
30 Auch Goldberg (1995: 213) weist bereits darauf hin (und zeigt dies an Korpusdaten), dass "[t]he subject referent need not be volitional, or even human, as long as the motion is construed as self-propelled“. Gleichzeitig zeigt sie, dass sich Ausnahmen für diese Beschränkung nachweisen lassen, nach denen auch unbelebte Entitäten belegt sind (vgl. Goldberg 1995: 213, 1996: 45-46). Dass damit ein offensichtlicher Widerspruch, zumindest aber eine inkonsistente Argumentation entsteht, scheint sie nicht zu sehen.
} 
(39) So \{[EREIGNIS mäandern] sich die nackten und verschlungenen Leiber durch die Werbung und über die Titel jener der Werbeästhetik folgenden Magazine\}. (Die Zeit, 13.01.2000, Nr. 3)

Auffällig ist, dass insbesondere die letzten drei diskutierten Beschränkungen in der neueren Forschung zur reflexiven Bewegungskonstruktion nahezu keine Rolle mehr spielen und teils, übereinstimmend mit den Befunden in meinen Daten, in Zweifel gezogen werden. So stellt Smirnova (2018: 35) fest, dass die einzig plausible Beschränkung auf ,Verben mit agentiver Semantik, die ein intentionales Subjekt/Agens aufweisen“ liegt. Beobachtungen hinsichtlich der Frage nach einer atelischen oder telischen Lesart der ,Bewegung' sowie einer Korrelation zwischen bestimmten Präpositionen (die die Köpfe der KtE des KE Weg bilden) und dem ,Schwierigkeitsgrad' der ,Bewegung ' formuliert sie vorsichtiger als Präferenzen (vgl. Smirnova 2018: 37-38). Diese Beobachtungen sehe ich als Argumente dafür, bei der Auswahl der Daten solchen semantischen Beschränkungen mit Vorsicht gegenüberzutreten. Grundsätzlich allerdings geben Präferenzen etwa für LE, die das KE EREIGNIS instanziieren und die bestimmte Frames evozieren und bestimmte lexikalische Bedeutungen tragen (vgl. Unterabschnitt 5.3.3), wichtigen Aufschluss über weitere semantische Eigenschaften der Konstruktion, die sich in den in Kapitel $5 \mathrm{zu}$ diskutierenden semantischen Parametern widerspiegeln. Es ist deshalb notwendig, zwischen (formalen und zum Teil semantischen) Beschränkungen auf der einen Seite und Präferenzen, etwa für bestimmte Frames und lexikalische Bedeutungen, auf der anderen Seite zu unterscheiden. Dafür führe ich einen dezidierten semantischen Parameter von Konstruktionen ein, der in Abschnitt 5.3 zu erläutern ist.

\subsubsection{Verwandte Konstruktionen}

Die reflexive Bewegungskonstruktion ist, wie bereits mehrfach erwähnt, nicht die einzige Konstruktion, die als deutsches Äquivalent der way-Konstruktion gelten kann. Ebenso ist sie nicht die einzige Konstruktion, deren semantische Eigenschaften auf einen Frame wie Motion zurückgehen. Bevor ich die reflexive Partikelverbkonstruktion (Abschnitt 3.2) und die reflexive Weg-Konstruktion (Abschnitt 3.3) ausführlicher vorstelle, möchte ich im Folgenden kurz auf ihre Verwandtschaft mit der reflexiven Bewegungskonstruktion eingehen, um damit auch zu begründen, warum die drei Konstruktionen einen zusammenhängenden Phänomenbereich bilden. Gemein ist allen drei Konstruktionen, dass es sich dabei um Reflexivkonstruktionen handelt, sie also ein KEE enthalten, das als Reflexivum instanziiert wird. Konstruktionen mit dieser Eigenschaft können als 
eine eigenständige Konstruktionsfamilie, eben als Reflexivkonstruktionen, verstanden werden (vgl. Lehmann 2017: 127; Boas, Lyngfelt \& Torrent 2019: 42). Wie bereits im Eingang zu diesem Kapitel erwähnt, kommen zwei Konstruktionen als zur reflexiven Bewegungskonstruktion besonders verwandt infrage.

- Die reflexive Partikelverbkonstruktion: Sie ist eine strukturell zur reflexiven Bewegungskonstruktion ähnliche Konstruktion, die über ein zweites KEE RICHTUNG verfügt, das durch eine Verbpartikel instanziiert wird, die gemeinsam mit einem Basisverb, das als KtE des KE EREIGNIS instanziiert wird, ein Partikelverb bildet.

- Die reflexive Weg-Konstruktion: Sie ist eine mit der way-Konstruktion strukturell nahezu identische Konstruktion, die sich von der reflexiven Bewegungskonstruktion hauptsächlich in einem zusätzlichen KorE unterscheidet, das mit der way-NP der way-Konstruktion zu vergleichen ist.

Kriterien für die Verwandtschaft der drei Konstruktionen sind somit einerseits formaler und andererseits semantischer Natur (vgl. dazu Engelberg 2019: 26; Boas, Lyngfelt \& Torrent 2019: 42-43; Endresen \& Janda 2020: 5-6): Ein formales Kriterium besteht in dem Vorhandensein eines Reflexivums als KEE, ein semantisches in einem gemeinsamen, mit allen drei Konstruktionen assoziierten Frame wie Moti on. ${ }^{31}$ Letzteres verstärkt die Verwandtschaft der Konstruktionen insofern, als dass sie nicht nur in formaler, sondern ebenso in semantischer Nähe in einem Konstruktikon verortet werden können. Auf weitere Aspekte der Verwandtschaft, besonders zwischen der reflexiven Bewegungskonstruktion und der reflexiven Partikelverbkonstruktion, gehe ich in Unterabschnitt 3.2.3 ein.

Das formale Verwandtschaftskriterium des Reflexivums als KEE führt nun allerdings dazu, dass Konstruktionen, die mit der reflexiven Bewegungskonstruktion semantisch verwandt sind und ihr auch strukturell ähneln, aber eben keine Reflexivkonstruktionen sind, ausgeklammert werden. Es handelt sich dabei insbesondere um Konstruktionen, deren Unterschied zur reflexiven Bewegungskonstruktion einzig im fehlenden Reflexivum besteht und die teilweise bereits unter dem Aspekt der Koerzion von ,Geräuschverben' zu ,Bewegungsverben' thematisiert worden sind (z.B. Engelberg 2009; Goschler 2011; Ziem \& Lasch 2013: 129140, 173-185). ${ }^{32}$ Damit ist allerdings nicht gesagt, dass sich diese Konstruktionen

31 Endresen \& Janda (2020: 6) knüpfen die formale Verwandtschaft von Konstruktionen unter anderem explizit an gemeinsame anchor words, also KEE, während sie die semantische Verwandtschaft in einer Synonymie zwischen Konstruktionen sehen, die in ihrem Modell allerdings nicht auf Frames beruht.

32 Engelberg et al. (2011: 97-98) diskutieren eine Instanz der reflexiven Bewegungskonstruktion als eine reflexive Variante einer Resultativkonstruktion, stellen deren Unterschied zu reflexiven 
nicht in einer Verwandtschaft der hier untersuchten Konstruktionen sehen lassen - die Verwandtschaft ist in diesem Fall jedoch in erster Linie semantischer und nicht formaler Natur. Ein Einbezug dieser Konstruktionen würde eine umfassendere Modellierung einer größeren Konstruktionsfamilie notwendig machen.

Vorstellbar ist, dass sich diese Konstruktionsfamilie in zwei Zweige aufspaltet: Einerseits in Konstruktionen, die als allgemeine ,Bewegungskonstruktionen bezeichnet werden könnten, ${ }^{33}$ da sie mit Moti ion assoziiert sind, allerdings nicht reflexiv sind, und andererseits Konstruktionen, die zusätzlich zu ihrer Eigenschaft als „Bewegungskonstruktionen“ noch Eigenschaften von Reflexivkonstruktionen erben, nämlich ein Reflexivum als KEE beinhalten. ${ }^{34}$ Nur dieser zweite, reflexive Zweig von ,Bewegungskonstruktionen“ konstituiert den Phänomenbereich der vorliegenden Arbeit und ist Kriterium für die Verwandtschaft der untersuchten Konstruktionen.

\subsection{Reflexive Partikelverbkonstruktion}

Als zweites deutsches Äquivalent zur way-Konstruktion lässt sich eine eher selten berücksichtigte ${ }^{35}$ Konstruktion annehmen, die bisweilen sowohl mit der wayKonstruktion als auch direkt mit der reflexiven Bewegungskonstruktion in Verbindung gebracht wird. Es handelt sich um eine Konstruktion, in deren Zentrum ein Partikelverb steht und deren Konstrukte die Belege (40)-(45) illustieren sollen.

(40) Die überrumpelte Frau will, man merkt es ihr an, keine Spielverderberin sein und \{ringt sich gegen spürbare Widerstände zum Mitmachen durch\}. (Die Zeit, 20.01.2000, Nr. 4)

(41) So \{mogelt sich Japan durch\}: bis auf den Buchstaben verfassungstreu, cool demokratisch und wohl wissend, dass große Politiker nicht immer

Resultativkonstruktionen, deren Resultativprädikat nicht durch eine PP (also gewissermaßen als KtE eines KE wie WEG), sondern durch ein Adjektiv ausgedrückt wird, allerdings nicht heraus.

33 Diesen Terminus nutzt auch Goschler (2011: 33) in der Diskussion um ,Geräusch-alsBewegung-Verben'.

34 Ein Konstruktikon-Ausschnitt dieser Art macht also die Annahme eines multiple inheritance model notwendig, nach dem eine Konstruktion Eigenschaften von mehreren übergeordneten Konstruktionen zugleich erben kann (vgl. dazu Ziem 2014c: 24), sofern man von Vererbungsrelationen im Sinne von Goldberg (1995: 72-81) als Basis für die Verwandtschaft von Konstruktionen ausgeht.

35 In der Arbeit von McColm (2019) etwa, die sich dezidiert den deutschen Äquivalenten der wayKonstruktion widmet, fehlt diese Partikelverbkonstruktion vollkommen. 
große Taten vollbringen - viel öfter das Gegenteil. (Die Zeit, 06.04.2000, Nr. 15)

(42) „Repetieren: morgen, in einer Woche, in einem Monat“ heißt Staubs Rezept, damit \{sich das Reingehämmerte bis ins Langzeitgedächtnis durchschlägt\}. (Die Zeit, 16.03.2000, Nr. 12)

(43) \{Michaela redete sich jedesmal heraus\}. (Schulze, Ingo: Neue Leben, Berlin: Berlin Verlag 2005, S. 577)

(44) \{Ich kämpfte mich hinaus $\}$ und stieg im Garten den Hang hinauf. (Schulze, Ingo: Neue Leben, Berlin: Berlin Verlag 2005, S. 159)

(45) Als ich die Augen schloß, war das Rot hinter meinen Lidern, und \{aus ihm schälten sich diese Backsteinhäuser des Lagers heraus\}. (Kuckart, Judith: Lenas Liebe, Köln: DuMont Literatur und Kunst Verlag 2002, S. 55)

Innerhalb eines konstruktionsgrammatischen Ansatzes können Instanzen wie diese nicht nur auf lexikalischer Basis ausgehend von Partikelverben analysiert, sondern als Konstrukte einer komplexen syntaktischen Konstruktion aufgefasst werden, die ich in Anlehnung an Knobloch (2009) und Dewell (2011: 1) als Partikelverbkonstruktion bezeichne, genauer: als reflexive Partikelverbkonstruktion (RPVKxn). ${ }^{36}$

In diesem Abschnitt möchte ich für die reflexive Partikelverbkonstruktion zunächst analog zur reflexiven Bewegungskonstruktion in Unterabschnitt 3.2.1 ihren Forschungsstand diskutieren sowie in Unterabschnitt 3.2.2 ihre Strukturelemente skizzieren, wobei ich besonders auf Gemeinsamkeiten und Unterschiede zur reflexiven Bewegungskonstruktion eingehe. Da sich diese beiden Konstruktionen in den Mengen ihrer jeweiligen Konstrukte überschneiden, gehe ich in Unterabschnitt 3.2.3 auf Überschneidungen zwischen der reflexiven Partikelverbkonstruktion und der reflexiven Bewegungskonstruktion ein, auch weil sich durch einen solchen Vergleich zentrale Charakteristika beider Konstruktionen sichtbar machen lassen, die für konstruktionssemantische Aspekte von Interesse und letztlich für eine konstruktikographische Modellierung relevant sind. Die reflexive Partikelverbkonstruktion kann wie die reflexive Bewegungskonstruktion als polysem betrachtet werden und weist dieselben vier Lesarten (Unterabschnitt 3.1.3) auf. Ich

36 Der Terminus Partikelverbkonstruktion findet sich bereits bei Olsen (1996b: 304), ohne dass der Begriff der Konstruktion genauer diskutiert wird. Felfe (2012: 3) spricht indes von „PartikelVerb-Komplexen“. Zur Rechtfertigung, von einer Konstruktion und nicht etwa von reflexiven Partikelverben zu sprechen, kann hier deutlicher als bei der reflexiven Bewegungskonstruktion das bereits erwähnte Distributionskriterium von Ágel (1997a: 181) dienen, da der Konstruktionsname bereits eine atypische, nämlich reflexive, Verwendung der involvierten Partikelverben impliziert. 
werde deren Illustration deshalb hier nicht wiederholen, sondern verweise auf die eingehendere Diskussion in Abschnitt 5.2. Dasselbe gilt für die anhand der reflexiven Bewegungskonstruktion diskutierten semantischen Beschränkungen (Unterabschnitt 3.1.4), auf sie komme ich in den Abschnitten 5.3 und 5.7 sowie 7.3 und 7.6 auch für die reflexive Partikelverbkonstruktion zurück.

\subsubsection{Forschungsstand}

In der konstruktionsgrammatischen Forschung bleibt die reflexive Partikelverbkonstruktion als Äquivalent zur way-Konstruktion nahezu unberücksichtigt, jedenfalls wird sie kaum als eigenständiger Phänomenbereich wahrgenommen, wenngleich Parallelen zur way-Konstruktion bisweilen erkannt werden. Da sie mit der reflexiven Bewegungskonstruktion einerseits die Eigenschaft einer Reflexivkonstruktion teilt (wie in Unterabschnitt 3.1.5 bereits ausgeführt), andererseits aber auch als Partikelverbphänomen betrachtet werden kann, findet sie sowohl in Forschungen zu Reflexivität als auch in Forschungen zu Partikelverben Erwähnung. Auf beide Forschungsstränge möchte ich im Folgenden eingehen.

In der Reflexivitätsforschung betrachtet schon Reis (1982: 4) Verben wie sich einschmeicheln als ,,abgeleitete Wörter, wobei das obligatorische sich erst Resultat des jeweiligen Wortbildungsprozesses ist, der aus einwertigen Grundverben Verbausdrücke vornehmlich resultativen Charakters ableitet.“ Auf ihre Beobachtungen bezugnehmend hält Kunze (1995: 21) eine Verwandtschaft einer solchen Partikelverbkonstruktion zur reflexiven Bewegungskonstruktion „für zutreffend“. Letztere sieht er indes als „eine Ableitung aus ursprünglichen Verbsememen“ (Kunze 1995: 21) an. Zudem hält er für die reflexive Bewegungskonstruktion fest: ,Das Direktional ist obligatorisch, es kann natürlich auch durch abtrennbare Verbzusätze realisiert werden (sich einschmeicheln/wegschleichen).“(Kunze 1995: 22). Dass mit dieser Eigenschaft aber der Übergang zu einer zweiten Konstruktion markiert ist, der reflexiven Partikelverbkonstruktion, zieht er nicht in Betracht.

Auch in der Partikelverbforschung wird bisweilen auf die reflexive Partikelverbkonstruktion hingewiesen, ohne sie jedoch als solche zu bezeichnen oder gar auf Parallelen zur reflexiven Bewegungskonstruktion hinzuweisen. Schon bei Kühnhold (1973: 184, 187, 263-264, 283) werden an mehreren Stellen Verbgebräuche wie sich einbohren, einschmeicheln, durcharbeiten, durchbetteln, durchboxen, durchkämpfen, durchmogeln, durchquälen, durchringen, durchschlagen, durchschwindeln oder sich einarbeiten, einleben oder einlesen diskutiert. Dass es sich dabei um eine syntaktische Konstruktion handeln muss, die eine eigene Argumentstruktur mit sich bringt, wird bereits festgehalten, wenn Kühnhold (1973: 184) für eine dieser Gruppen von Verben (sich einnisten, einbohren, ein- 
schmuggeln, einfühlen) feststellt:: „Bei der guten Hälfte der refl[exiven] Fälle ist das Grundverb nicht refl[exiv]“. Auch eine Eigenschaft, die die reflexive Partikelverbkonstruktion von der reflexiven Bewegungskonstruktion unterscheidet (vgl. Unterabschnitt 3.2.2), wird von Kühnhold (1973: 184) - hier exemplarisch an einer Gruppe von Verben - bereits bemerkt: „Während beim Simplex die Präpositionalfügung mit in obligatorisch ist, ist sie beim Präfixverb [in heutiger Terminologie: Partikelverb, A.W.] fakultativ und bleibt häufig weg“.

Wie Kühnhold ist Mungan (1986: 117) zur frühen Partikelverbforschung zu zählen, die die reflexive Partikelverbkonstruktion zumindest zur Kenntnis nimmt. Sie listet entsprechende Bildungen mit der Partikel durch als eine eigene semantische Gruppe auf und paraphrasiert die Bedeutung von Verben wie durchboxen, durchdringen und durchkämpfen mit „,sich gewaltsam bzw. mit Mühe einen Weg durch ein Hindernis hindurch bahnen“" (Mungan 1986: 117), womit sie nicht nur den semantischen Aspekt einer (ggf. metaphorischen) ,Bewegung ' herausarbeitet, sondern interessanterweise gleichermaßen auf den für die way-Konstruktion intensiv diskutierten Aspekt der ,Schwierigkeit‘ (Unterabschnitt 3.1.4) hinweist.

McIntyre (2001: 24) erwähnt die Konstruktion als deutsches Pendant der way-Konstruktion ausgehend von der Diskussion Letzterer bei Levin \& Rapoport (1988). Ebenso als eine direkte Parallele zur way-Konstruktion sieht Dewell (2011: 62, Anm. 3) reflexive Instanzen mit der Partikel durch an. Bei Müller (2002: 300, Anm. 123) findet sich lediglich ein marginaler Hinweis zu Verben wie sich durchfragen oder sich hochdienen, die er unter Rückgriff auf die way-Konstruktion ins Englische übersetzt, ohne jedoch die Konstruktion als solche zu thematisieren. Auch in den von Chang (2008: 129) im Kontext von Resultativkonstruktionen diskutierten Belegen findet sich ein Konstrukt, das als eines der reflexiven Partikelverbkonstruktion gelten kann, was den fließenden Übergang zwischen ihr und ,echteren' Resultativkonstruktionen verdeutlicht (zu Möglichkeiten der Abgrenzung vgl. weiterhin Chang 2008: 134-139).

Am Rande äußert auch Oya (1999: 365) die Vermutung, dass semantisch mit der reflexiven Bewegungskonstruktion identische, „oft verwendete Ausdrücke, [...], lexikalisiert werden“ und zählt eine Reihe von Verben wie sich durcharbeiten, sich einhören oder sich vorkämpfen als Beispiele auf. Bezüge zwischen der reflexiven Bewegungskonstruktion und der reflexiven Partikelverbkonstruktion stellt neben Oya (1999: 365) im Ansatz auch Smirnova (2018) her. Smirnova (2018: 35, Anm. 7) bemerkt das Auftreten von Verbpartikeln im Zusammenhang mit Kon-

37 Mit Verweis auf Kühnhold (1973) bemerkt Knobloch (2009: 546), dass „,[d]ie klassische Einteilung der Partikelverben, [...], [...] im Grunde bereits so etwas wie die Aufteilung der Bildungen in Konstruktionsbedeutungen“ darstellt. 
strukten der reflexiven Bewegungskonstruktion und stuft die Frage nach dem Status dieser Verbpartikeln als Desiderat ein.

All diese Beobachtungen nehme ich zum Anlass, die reflexive Partikelverbkonstruktion als zweites deutsches Äquivalent zur way-Konstruktion zu betrachten.

\subsubsection{Strukturelemente}

Die formale Verwandtschaft der reflexiven Partikelverbkonstruktion zur reflexiven Bewegungskonstruktion ist offenkundig daran zu erkennen, dass zahlreiche Verbpartikeln im Deutschen semantisch mit formidentischen Präpositionen zu vergleichen sind (vgl. dazu Gerdes 2016: 19), ${ }^{38}$ die prinzipiell einen Bezug zu den Präpositionen, die die Köpfe der KtE des KE WEG der reflexiven Bewegungskonstruktion darstellen, ermöglichen. ${ }^{39}$ Darüber hinaus fällt beim Vergleich der reflexiven Bewegungskonstruktion mit der reflexiven Partikelverbkonstruktion auf, dass sich beide formal teilweise überlappen: Auch für die reflexive Bewegungskonstruktion kann angenommen werden, dass sie Partikelverben als KtE des KE EREIGNIS erlaubt. Allerdings lassen sich drei wesentliche Unterschiede zur reflexiven Bewegungskonstruktion feststellen, die es rechtfertigen, die reflexive Partikelverbkonstruktion als eigenständige Konstruktion zu betrachten.

Bevor ich diese Unterschiede im Einzelnen betrachte und in Unterabschnitt 3.2.3 konkreter auf die Überschneidung zwischen reflexiver Partikelverbkonstruktion und reflexiver Bewegungskonstruktion eingehe, seien die Konstrukte in den im Eingang zu diesem Abschnitt zitierten Belegen (40)-(45) zunächst auf ihre sich teilweise mit der reflexiven Bewegungskonstruktion überschneidenden Strukturelemente hin in (46)-(51) annotiert.

(46) Die überrumpelte Frau will, man merkt es ihr an, keine Spielverderberin sein und \{[EREIGNIS ringt] [KEE sich] gegen spürbare Widerstände [〈WEG $\rangle$ zum Mitmachen] [RIchтung durch]\}. (Die Zeit, 20.01.2000, Nr. 4)

38 Stiebels (1996: 83) bemerkt, dass Partikeln semantisch nah an Präpositionen zu verorten sind, wenn sie in eine Argumentsättigung des Basisverbs involviert sind, also ein Argument des Basisverbs besetzen. Wie dies bei anderen Varianten des Einflusses der Partikel auf die Argumentstruktur des Basisverbs (vgl. die Übersicht in Stiebels 1996: 57) aussieht, lässt sie allerdings offen.

39 Für ,Geräusch-als-Bewegung-Verben' schreibt auch Goschler (2011: 27) sowohl direktionalen PP als auch Verbpartikeln dieselbe koerzierende Leistung zu. Vgl. für das Englische auch Rohde (2001: 64). 
(47) So \{[EReignis mogelt] [KeE sich] [Bewegendes Japan] [Richtung durch]\}: bis auf den Buchstaben verfassungstreu, cool demokratisch und wohl wissend, dass große Politiker nicht immer große Taten vollbringen - viel öfter das Gegenteil. (Die Zeit, 06.04.2000, Nr. 15)

(48) „Repetieren: morgen, in einer Woche, in einem Monat“ heißt Staubs Rezept, damit $\left\{\right.$ KKEE $_{\text {Sich] [BEwEGENDES }}$ das Reingehämmerte] [ ${ }_{\langle\mathrm{WEG}\rangle}$ bis ins Langzeitgedächtnis] [RIchtung durch][EREIGNis schlägt]\}. (Die Zeit, 16.03.2000, Nr. 12)

(49) $\{$ [Bewegendes Michaela] [EReignis redete] [KeE sich] jedesmal [Richtung heraus]\}. (Schulze, Ingo: Neue Leben, Berlin: Berlin Verlag 2005, S. 577)

(50) $\{$ [Bewegendes Ich] [EREIGnis kämpfte] [KEE mich] [Richtung hinaus] $\}$ und stieg im Garten den Hang hinauf. (Schulze, Ingo: Neue Leben, Berlin: Berlin Verlag 2005, S. 159)

(51) Als ich die Augen schloß, war das Rot hinter meinen Lidern, und $\left\{\left[\left\langle\mathrm{WEG}_{\mathrm{EG}}\right\rangle\right.\right.$ aus ihm] [EREIGNis schälten] [KEE sich] [BEwEgEndes diese Backsteinhäuser des Lagers] [RIchtung heraus]\}. (Kuckart, Judith: Lenas Liebe, Köln: DuMont Literatur und Kunst Verlag 2002, S. 55)

Der erste Unterschied zwischen den beiden Konstruktionen besteht darin, dass die reflexive Partikelverbkonstruktion das $\mathrm{KE}\langle\mathrm{WEG}\rangle$, anders als die reflexive Bewegungskonstruktion, nicht obligatorisch realisieren muss (vgl. schon Olsen 1997b: 17). ${ }^{40}$ Es handelt sich dabei konstruktikographisch formuliert um ein Nicht-KernKE (Unterabschnitt 2.3.1).41 Ist als KtE des KE EREIGNIS das Basisverb eines Partikelverbs instanziiert, kann das KE 〈WEG ) uninstanziiert bleiben, wie ein Vergleich von Konstrukten der reflexiven Bewegungskonstruktion mit Nicht-Partikelverben - nachfolgend unter a - und Konstrukten der reflexiven Partikelverbkonstruktion ohne Instanziierung des KE $\langle\mathrm{WEG}\rangle$ - nachfolgend unter b - zeigt. Dies wird besonders deutlich, wenn, wie in den Konstrukten in (52)-(53), Verbpartikel und Basisverb in Distanzstellung realisiert werden.

40 Knobloch (2009: 552-553) führt dieses Charakteristikum ganz konkret auf das Erscheinen eines Partikelverbs im Gegensatz zu einem simplizischen Verb zurück.

41 Allerdings ist damit nicht die Implikation beabsichtigt, das Nicht-Kern-KE korrespondiere systematisch mit dem Nicht-Kern-FE eines Frames. Ich komme darauf ausführlicher in Unterabschnitt 6.4.2 zurück. Für die Benennung des KE 〈WEG〉 gelten indes dieselben Grundsätze wie für die reflexive Bewegungskonstruktion, vgl. dazu schon Unterabschnitt 3.1.2 sowie ausführlicher Unterabschnitt 7.3.3. 
(52) a. $\{$ [Bewegendes Riesige Schwimmbagger] [EReignis fressen] [KeE sich] einmal [WEG durch den Dünengürtel]\}, zweigen das Titan ab (der Vorrat hätte für gerade mal 17 Jahre gereicht) und spucken den wertlosen Rest wieder aus. (Die Zeit, 27.01.2000, Nr. 5)

b. Der Gestank, der trotz des Regens in der Luft liegt, ist so widerlich, daß sogar die Fliegen fortbleiben; nur die Ratten vermehren sich, $\{[$ EREIGNIS fressen] [KEE sich] [RICHTUNG durch]\} und bauen sich Nester in den fauligen Eingeweiden. (Schrott, Raoul: Tristan da Cunha oder die Hälfte der Erde; Hanser Verlag 2003, S. 256)

(53) a. $\quad\{$ [Bewegendes Der Vater] [EReignis schlug] [KEe sich] [Weg durch die Hausund Gartentür, die danach, und für Jahre, schräg in den Angeln hing]\}. (Widmer, Urs: Das Buch des Vaters, Zürich: Diogenes 2004, S. 153)

b. Du weißt ja wahrscheinlich, daß sie nach München gegangen ist, sie war auf dieser Schauspielschule, ich weiß nicht, wir telefonieren ab und $\mathrm{zu}$, sie hat geheiratet, aber es war nichts, und jetzt ... \{[EREIGNIS schlägt] [KEE sich] so [Richtung durch]\}. (Kopetzky, Steffen: Grand Tour, Frankfurt am Main: Eichborn 2002, S. 76)

Der zweite Unterschied betrifft ebenfalls das KE 〈WEG〉, nun aber seine Form. Neben seiner Realisierung als PP wie bei dem KE WEG der reflexiven Bewegungskonstruktion kann das KE 〈WEG〉 der reflexiven Partikelverbkonstruktion auch in Form einer NP realisiert werden. Häufiger belegt sind hierfür NP im Akkusativ, ${ }^{42}$ vgl. dazu die Belege in (54).

(54) a. Katharina fühlt die Tränen im Hals, die sie nicht hochkommen lassen will, \{sie kratzen und beißen und ätzen sich [〈WEG ${ }_{\text {die Speiseröhre] }}$ hinab\} - den Ösophagus -, wo ist denn ihre Mutter, warum darf sie sie nicht einmal trösten? (Dölling, Beate: Hör auf zu trommeln, Herz, Weinheim: Beltz \& Gelberg 2003, S. 202)

b. \{Über Serpentinen quält sich der Autobus [ ${ }_{\langle\mathrm{WEG}\rangle}$ einen Pass] hinauf, und die Welt ist wieder verwandelt. (Die Zeit, 05.01.2000, Nr. 2)

c. Das Klöppeln kam von diesen offensichtlich hölzernen Stäben, mit denen $\left\{\right.$ sich die drei ${ }_{\langle\mathrm{WEG}\rangle}$ die Schillerstraße] hinaufstocherten\}. (Kopetzky, Steffen: Grand Tour, Frankfurt am Main: Eichborn 2002, S. 281)

d. Es war nicht besonders schnell, doch zum Glück machen die Straßen hier viele, viele Kurven, und irgendwann sah ich sie noch mal, tief unten im Tal, während \{ich mich noch [〈WEG

42 Bei Harnisch (1982: 119) wird eine solche Phrase als „Ortsobjekt“ bezeichnet, das unter anderem im „Objektsakkusativ“ auftreten kann. Eine dativische Variante zieht er nicht in Erwägung. 
quälte\}. (Funke, Cornelia: Tintenherz, Hamburg: Cecilie Dressler Verlag 2003, S. 105)

Vereinzelt sind auch NP im Dativ belegt, wie die Belege in (55) zeigen (vgl. dazu auch Olsen 1996a: 274, 1997b: 18, 1999: 232-233).

a. In gewisser Weise, antwortete er und sah erst gründlich aus dem Fenster, bevor $\{$ er sich $[\langle\mathrm{WEG}\rangle \mathrm{mir}]$ wieder zuwandte\}. (Schmitter, Elke: Frau Sartoris, Berlin: BvT 2000[2002], S. 118)

b. Und $\left\{\right.$ Hermann beugte sich [ ${ }_{\langle\mathrm{WEG}\rangle}$ Sargnagels Ohr] zu\} und raunte: (Koneffke, Jan: Paul Schatz im Uhrenkasten, Köln: DuMont Buchverlag 2000, S. 136)

Neben der Realisierung als NP kann das KE 〈WEG〉 auch als Nebensatz mit $z u$ Infinitiv realisiert werden. Erscheint die Partikel in Kontaktstellung zum Basisverb, ist, wie in (56), allein dieser Nebensatz KtE des KE 〈WEG〉. Erscheint die Partikel in Distanzstellung zum Basisverb, enthält der Matrixsatz ein Korrelat wie etwa $d a z u$, wie in (57) zu sehen. Das KE 〈WEG〉 wird in diesem Fall wie das Partikelverb diskontinuierlich realisiert, ${ }^{43}$ einerseits durch das Korrelat im Matrixsatz, andererseits durch den Nebensatz.

(56) Als das Spiel fertig war, wollte Nintendo den Game-Boy gerade wieder vom Markt nehmen, weil er veraltet war, und dass \{man sich im Sommer 1996 überhaupt herabließ, [〈WEG $\rangle$ dieses merkwürdige Spiel zu vertreiben]\}, geschah in der vagen Hoffnung, an den Erfolg des virtuellen Computervogels Tamagotchi anknüpfen zu können. (Die Zeit, 23.03.2000, Nr. 13)

(57) a. Erst in letzter Minute \{rang sich Sartre $\left[\langle\mathrm{WEG}\rangle\right.$ dazu] durch, $\left[\left\langle{ }_{\text {WEG }}\right\rangle\right.$ den Einmarsch in Budapest 1956 zu verurteilen]\}, während sieben Jahre später die Sowjetunion wieder ,das einzige Land ist, wo das Wort Fortschritt noch einen Sinn hat“. (Die Zeit, 13.04.2000, Nr. 16)

b. Und so \{rang sich die Gesellschaft ${ }_{\left\langle\mathrm{WEG}_{\mathrm{EG}}\right\rangle}$ dazu] durch, ${ }_{\langle\mathrm{WEG}\rangle}$ dem Mann ein ganzes Paket von Privilegien zuzugestehen, die dafür sorgten, daß sich Vaterschaft lohnte und halbwegs sicher schien]\}. (Schwanitz, Dietrich: Männer, Frankfurt a. M.: Eichborn 2001, S. 28)

Diese im Gegensatz zur reflexiven Bewegungskonstruktion größere formale Varianz der KtE des KE 〈WEG〉 gibt Anlass zu der Annahme, dass es sich bei der Konstruktion um eine explizite Partikelverbkonstruktion handeln muss. Als KtE des

43 Ich übertrage die Prinzipien von FrameNets Annotation diskontinuierlich realisierter FE (Ruppenhofer et al. 2016: 38-41) hier auf KE. 
KE EREIGNIS muss also das Basisverb eines Partikelverbs instanziiert werden, da eine Instanziierung des KE WEG der reflexiven Bewegungskonstruktion durch eine NP oder einen Nebensatz bei simplizischen Verben als KtE des KE EREIGNIS nicht möglich ist. Um diesem Umstand Rechnung zu tragen, muss die Modellierung der reflexiven Partikelverbkonstruktion im Gegensatz zur reflexiven Bewegungskonstruktion einen dritten Unterschied aufweisen: Es muss ein obligatorisches Strukturelement für die Partikel geben. Da „Verbpartikeln in der Regel als richtungsspezifizierende Elemente“ (Gerdes 2016: 12) verstanden werden, liegt es nahe, diesem Strukturlement den Namen RIcHTUNG zu geben, wie ich es in den Annotationen in (46)-(51) umgesetzt habe. ${ }^{44}$ Die Partikelverben in dieser Konstruktion werden somit durch zwei Strukturelemente repräsentiert: EREIGNIS wird durch simplizische Basisverben als KtE instanziiert, während durch RICHTUNG die jeweilige Partikel instanziiert wird. Damit kann die produktive Instanziierung der Konstruktion durch LE, die ansonsten distributionell nicht als Basisverben von Partikelverben gelten können (z.B. arbeiten, kämpfen, mogeln, schlagen), dargestellt werden. ${ }^{45}$ Die in der Partikelverbforschung umstrittene Frage, ob Partikelverben zur Morphologie oder zur Syntax zu zählen sind (vgl. den Überblick in Nöhren 2019: 11-31) ${ }^{46}$ stellt sich somit in diesem Beschreibungsformat erst gar nicht. Ob eine Kombination aus KE, KEE und KorE morphologischen oder syntaktischen Charakter hat, ist vor dem Hintergrund der Annahme eines Lexikon-GrammatikKontinuums im Sinne von Langacker (1987: 3) unerheblich (vgl. auch Michel 2014: 139-140). ${ }^{47}$ Gleiches gilt für KE, KEE und KorE selbst: Es muss nicht für eine Konstruktion spezifisch festgelegt werden, ob es sich bei ihren Instanzen um Morpheme, Phrasen oder Sätze handelt. ${ }^{48}$

44 Vgl. dazu auch die These von McIntyre (2001: 15-19), dass Verbpartikeln eine eigenständige Bedeutung zukommt und Partikelverben nicht (allein) aus morphologischen Analogiebildungen resultieren.

45 Zur Annahme, dass Basisverben als Köpfe von Partikelverbkonstruktionen gelten können, vgl. Stiebels (1996: 38) und Müller (2002: 253). Konstruktionssemantisch wird diesem Umstand dadurch Rechnung getragen, dass das in diesem KE instanziierte KtE eine LE, die einen lexikalischen Frame (Abschnitt 4.2) evoziert, darstellt (dazu auch Unterabschnitt 7.3.1).

46 Vgl. die treffende Bemerkung von Müller (2007: 181): „Bei den Partikelverben, die sich in vielerlei Hinsicht parallel [zu Resultativkonstruktionen, A.W.] verhalten, toben [...] erbitterte Kämpfe, ob sie in der Morphologie oder in der Syntax zu analysieren sind.“

47 Anders als in der Konstruktionsgrammatik allgemein (vgl. für eine Programmatik und einen Überblick Michel 2014) sind morphologische Aspekte in der Konstruktikographie noch tendenziell unterrepräsentiert.

48 Inwiefern dadurch den Vorbehalten von Müller (2007: 188-192, 198-199), nach denen wortstellungsspezifizierte Konstruktionen angenommen werden müssten, was zu einer inflationären Vermehrung von Konstruktionen führen würde, begegnet werden kann, muss offen bleiben. Je- 
Das Strukturelement Richtung steht in seinem Status nahezu in der Mitte zwischen KEE und KE. Einerseits ist es soweit lexikalisch fixiert, dass es - ähnlich wie die KEE aller drei untersuchten Konstruktionen - nur eine kleine Bandbreite lexikalischer Elemente als Instanziierungen zulässt. ${ }^{49}$ Andererseits aber ist diese Bandbreite größer als diejenige des als Reflexivum instanziierten KEE, für das ich, wie in Abschnitt 3.1.2 argumentiert, ebenso bereits von der strengen Definition von KEE abgewichen bin. Das Strukturelement RICHTUNG lässt grundsätzlich alle Verbpartikeln als Instanzen zu, die semantisch eine ,Direktionalität‘ kodieren können (vgl. Tabelle 3.5 in Unterabschnitt 3.4.2). Da diese Bandbreite aber wiederum deutlich kleiner ist als etwa diejenige der möglichen KtE des KE EREIGNIS, die potenziell jedes simplizische Verb umfassen kann, betrachte ich das Strukturelement RIcHTUNG als näher am Status eines KEE als eines KE, vergleiche es also grundsätzlich mit dem zweiten, unmittelbar als solches benannten KEE, das durch ein Reflexivum instanziiert wird.

Tabelle 3.2 listet die insgesamt fünf Strukturelemente der reflexiven Partikelverbkonstruktion samt ihrer vorläufigen Definitionen auf.

\subsection{3 Überschneidungen mit der reflexiven Bewegungskonstruktion}

Vor dem Hintergrund insbesondere der soeben skizzierten formalen Varianz der KtE des KE 〈WEG〉 der reflexiven Partikelverbkonstruktion lässt sich der Bereich, in dem sich diese mit der reflexiven Bewegungskonstruktion überschneidet, genauer lokalisieren. Beide Konstruktionen überschneiden sich, wenn in einem Konstrukt der reflexiven Bewegungskonstruktion als KtE des KE EREIGNIS ein Partikelverb instanziiert wird und in einem Konstrukt der reflexiven Partikelverbkonstruktion das KE 〈WEG〉 als PP instanziiert wird. Instanzen, die eindeutig als Konstrukte der reflexiven Bewegungskonstruktion gelten, sind also nur solche, in denen Nicht-Partikelverben als KtE des KE EREIGNIs instanziiert werden. Auf Seiten der reflexiven Partikelverbkonstruktion sind eindeutige Konstrukte zunächst solche, in denen das KE 〈WEG〉 als NP oder Nebensatz instanziiert wird. Am eindeutigsten zur reflexiven Partikelverbkonstruktion gehören indes diejenigen Konstrukte,

denfalls bemerkt Goldberg (2006: 10), dass Konstruktionen nicht auf bestimmte Wortstellungen festgelegt werden müssen. Müller ist jedoch insofern zuzustimmen, als dass diese Regularitäten konstruktionsgrammatisch erfasst werden müssen. Wie dies konstruktikographisch geschehen muss, ist bislang ungeklärt und kann hier nicht weiter thematisiert werden.

49 Zur Annahme, dass Verbartikeln in Partikelverbkonstruktionen als lexikalisch spezifiziert angesehen werden müssen und die Konstruktionen entsprechend teilspezifiziert sind, vgl. schon Booij (2002: 320-325). 
Tab. 3.2: Strukturelemente der reflexiven Partikelverbkonstruktion

\begin{tabular}{|c|c|}
\hline Strukturelement & Vorläufige Definition \\
\hline BEWEGENDES & $\begin{array}{l}\text { Die KtE dieses KE referieren auf eine (belebte oder unbelebte) Entität, die ei- } \\
\text { ne ,Bewegung، ausführt. Die Entität, auf die ein KtE dieses KE referiert, muss } \\
\text { mit derjenigen, auf die das KEE referiert, identisch sein. }\end{array}$ \\
\hline EREIGNIS & $\begin{array}{l}\text { Die KtE dieses KE referieren auf ein Ereignis, das als eine ,Bewegung' der } \\
\text { Entität, auf die die KtE des KE BEWEGENDES referieren, verstanden werden } \\
\text { kann oder mit dieser,Bewegung einhergeht. Das KE wird durch ein Basisverb } \\
\text { instanziiert, das gemeinsam mit dem KEE RICHTUNG ein Partikelverb bildet. }\end{array}$ \\
\hline KEE & $\begin{array}{l}\text { Das KEE wird durch ein Reflexivum (im weitesten Sinne) instanziiert. Da- } \\
\text { bei kann es sich um das, echte‘ Reflexivpronomen sich oder ein reflexiv ge- } \\
\text { brauchtes Personalpronomen in 1. oder } 2 \text {. Person handeln. Handelt es sich } \\
\text { um Letzteres, muss es auf dieselbe Entität wie das KtE des KE BEWEGENDES } \\
\text { referieren. }\end{array}$ \\
\hline RICHTUNG & $\begin{array}{l}\text { Das KEE RICHTUNG wird durch eine Verbpartikel instanziiert und bildet zusam- } \\
\text { men mit dem KtE des KE EREIGNIS ein Partikelverb. Es kann dabei sowohl in } \\
\text { Distanzstellung zum Basisverb als auch in Kontaktstellung realisiert werden. }\end{array}$ \\
\hline$\langle\mathrm{WEG}\rangle$ & $\begin{array}{l}\text { Die KtE dieses Nicht-Kern-KE elaborieren die räumliche Ausdehnung der ,Be- } \\
\text { wegung der Entität, auf die das KtE des KE BEWEGENDES referiert, welche } \\
\text { bereits durch das KEE RICHTUNG Spezifiziert ist. Aus diesem Grund ist 〈WEG } \\
\text { als Nicht-Kern-KE einzustufen: Da die räumliche Ausdehnung der ,Bewegung“ } \\
\text { bereits durch die Instanz des KEE RICHTUNG spezifiziert wird, kann es unin- } \\
\text { stanziiert bleiben. }\end{array}$ \\
\hline
\end{tabular}

die ohne Instanziierung des KE 〈WEG〉 auskommen. In Abbildung 3.1 soll die Nähe letzterer Konstrukte zum Rand des unteren Rechtecks diese Unterscheidung ausdrücken, während die anderen beiden Varianten tendenziell näher am Überschneidungsbereich zur reflexiven Bewegungskonstruktion liegen.

Trotz der Unterschiede in der formalen Realisierung der reflexiven Partikelverbkonstruktion bereitet die Überschneidung mit der reflexiven Bewegungskonstruktion auf den ersten Blick Probleme: Ist ein Beleg mit einem Partikelverb und einem als PP realisierten KtE des KE WEG bzw. 〈WEG〉 als Konstrukt der reflexiven Bewegungskonstruktion oder der reflexiven Partikelverbkonstruktion einzustufen? Dieses Zuordnungsproblem besteht freilich nur dann, wenn man beide Konstruktionen als disjunkte Kategorien versteht, die etwa in einer klar definierbaren Vererbungsrelation zueinander stehen, wie sie etwa Goldberg (1995: 7281) annimmt. Aufgrund der skizzierten Überschneidungen zwischen beiden Konstruktionen ist eine mögliche Vererbungsrelation allerdings schwierig zu postulieren. Deshalb bietet es sich an, die Relation zwischen beiden Konstruktionen nicht als Vererbung im Sinne einer Netzwerkrelation, sondern angelehnt an die Ansätze von Bücker (2011), Engelberg et al. (2011: 77-93), Proost \& Winkler (2015: 


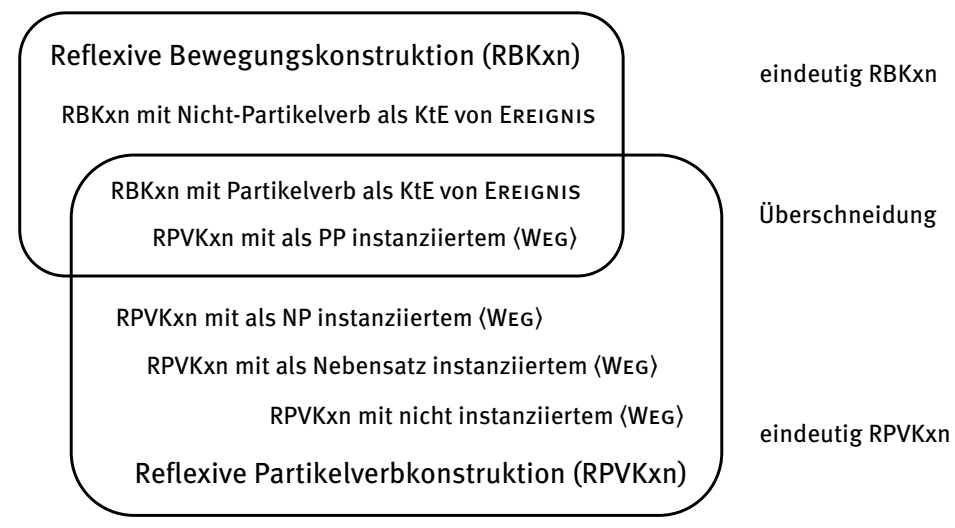

Abb. 3.1: Überschneidung zwischen der reflexiven Bewegungskonstruktion (RBKxn) und der reflexiven Partikelverbkonstruktion (RPVKxn)

8-11) sowie Proost (2017: 28-29) als Familienähnlichkeiten im Sinne von Wittgenstein (2009: § 67) ${ }^{50}$ zu betrachten. ${ }^{51}$ Wie Proost \& Winkler (2015: 9) und Engelberg (2019: 26) ausführen, können solche Familienähnlichkeiten sowohl formale als auch semantische Eigenschaften der Konstruktionen betreffen. Dasselbe halten Boas, Lyngfelt \& Torrent (2019: 42-43) und Endresen \& Janda (2020: 5-6) für die Zusammengehörigkeit von Konstruktionen zu einer Konstruktionsfamilie fest. Boas, Lyngfelt \& Torrent (2019: 42-43) definieren die semantische Zusammengehörigkeit von Konstruktionen dabei explizit als Evokation desselben Frames durch die Konstruktionen. Auch Diessel (2019: 200) betont, dass die Ähnlichkeit zwischen Konstruktionen ein wesentlicher Faktor für ihre Relationen zueinander ist.

Angewendet auf die reflexive Partikelverbkonstruktion im Vergleich zur reflexiven Bewegungskonstruktion stellen sich die Ähnlichkeiten beider Konstruktionen wie folgt dar.

- Ähnlichkeiten in der Form: Die reflexive Partikelverbkonstruktion teilt ihr Inventar der KE BEWEGENDES und EREIGNIS, dem KEE, sowie zumindest teilweise dem $\mathrm{KE}\langle\mathrm{WEG}\rangle$ mit der reflexiven Bewegungskonstruktion.

50 Auch Goldberg \& Jackendoff (2004: 536) bringen ihren Begriff der Konstruktionsfamilie mit demjenigen der Familienähnlichkeiten in Verbindung, jedoch ohne darauf theoretisch aufzubauen. Proost \& Winkler (2015: 9) stellen die Unterschiede ihres Ansatzes zu demjenigen von Goldberg \& Jackendoff (2004: 536) heraus.

51 Das Konzept der Familienähnlichkeiten wird bisweilen sogar, etwa mit dem Vorschlag von Gerdes (2016: 50), in der Partikelverbforschung zur Strukturierung von Kategorien von Partikelverben aufgegriffen. 
- Ähnlichkeiten in den semantischen Eigenschaften: Der reflexiven Partikelverbkonstruktion liegt - wie der reflexiven Bewegungskonstruktion und der reflexiven Weg-Konstruktion - Motion als von ihr evozierter Konstruktions-Frame (Abschnitt 4.3) zugrunde.

Beide Konstruktionen sind somit nicht scharf voneinander abzugrenzen, sondern zwischen ihnen liegt ein Graubereich von Instanzen, die sowohl als Konstrukte der einen als auch als Konstrukte der anderen Konstruktion eingestuft werden können. Aufgrund von Beobachtungen wie diesen geht Bücker (2011: 9-10) davon aus, dass sich Familienähnlichkeiten lediglich auf Konstruktebene (TokenEbene) niederschlagen, während auf Konstruktionsebene (Type-Ebene) nach wie vor von Netzwerkrelationen gesprochen werden muss. Entsprechend bestimme ich in Abbildung 3.1 den Grad der Überschneidung zwischen beiden Konstruktionen anhand der Realisierung ihrer Konstrukte. Die oben in zwei Punkten skizzierten Gemeinsamkeiten zwischen beiden Konstruktionen sind letztlich auf Familienähnlichkeiten zwischen ihren Konstrukten zurückzuführen. Die Modellierung einer Netzwerkrelation zwischen beiden Konstruktionen wird dadurch potenziell schwieriger, denn, wie Bücker (2011: 36) weiterhin konstatiert, korreliert der Grad an Familienähnlichkeit zwischen Konstrukten mit demjenigen der Netzwerkrelation zwischen den entsprechenden Konstruktionen: Je stärker die Familienähnlichkeiten ausgeprägt sind, desto plausibler ist die Annahme einer gemeinsamen Konstruktion, während mit der Abnahme von Familienähnlichkeiten eher disjunkte Konstruktionen mit oder ohne Relationen zwischen ihnen anzusetzen sind. Da zwischen der reflexiven Bewegungskonstruktion und der reflexiven Partikelverbkonstruktion zwar die skizzierten formalen und semantischen Gemeinsamkeiten auffindbar sind, sie sich aber gerade in formaler Hinsicht in drei wesentlichen Punkten unterscheiden (im Falle der reflexiven Partikelverbkonstruktion dem Status des KE 〈WEG $\rangle$ als Nicht-Kern-KE, dessen größerer formaler Varianz sowie dem zusätzlichen KEE RICHTUNG), gehe ich davon aus, dass es sich um zwei eigenständige Konstruktionen handelt.

\subsection{Reflexive Weg-Konstruktion}

Neben der reflexiven Bewegungskonstruktion und der reflexiven Partikelverbkonstruktion kann die in diesem Abschnitt vorzustellende Konstruktion, die mit Verhagen (2003a: 338, 2003c: 228), Smirnova (2018: 24) und Mortelmans \& Smirnova (2020: 47) als reflexive Weg-Konstruktion (Weg-Kxn) bezeichnet werden kann, als drittes Äquivalent zur way-Konstruktion gelten. Einige ihrer Konstrukte finden sich in (58)-(62). 
(58) Dann \{bahnte ich mir einen Weg durch allerlei Buschwerk und trockenes Gehölz\}. (Düffel, John von: Vom Wasser, München: dtv 2006, S. 214)

(59) \{Mein Schälmesser mit der dünnen Klinge säbelt sich einen Weg durch die buschigen Petersilienköpfe\}, während ich überlege, ob es tatsächlich Köpfe oder doch Blätter oder gar Büschel heißt. (Riedel, Susanne: Eine Frau aus Amerika, Berlin: Berlin Verlag 2003, S. 106)

(60) Längst \{müssen sich die hölzernen Schubkarren einen Weg zwischen den Fässern bahnen\}. (Die Zeit, 30.03.2000, Nr. 14)

(61) Als doppelter Fremder, der von einer fernen Insel und aus einer anderen Zeit kommt, \{bahnt er sich zielstrebig den Weg zum Mörder seiner Tochter\}. (Die Zeit, 05.01.2000, Nr. 2)

(62) In dieser Sekunde trat, überraschend und effektvoll, meine Mutter durch die Tür des Wintergartens, \{bahnte sich einen Weg zwischen den Adjutanten hindurch\}. (Krausser, Helmut: Eros, Köln: DuMont 2006, S. 48)

Die reflexive Weg-Konstruktion ist, anders als die reflexive Bewegungskonstruktion und die reflexive Partikelverbkonstruktion, ein formal näheres Äquivalent des Deutschen zur englischen way-Konstruktion. In der deutschsprachigen Forschung wird sie allerdings eher selten als direktes Äquivalent zur way-Konstruktion betrachtet, einzig McColm (2019) räumt ihr, wie bereits in Unterabschnitt 3.1.1 erwähnt, eine größere Rolle ein. Mortelmans \& Smirnova (2020: 59-60) gehen im diametralen Gegensatz dazu davon aus, dass ,there are no compelling reasons to assume the existence of a (schematic, non-compositional) Weg-construction in German.“ Ich möchte einen Mittelweg zwischen diesen beiden Positionen einschlagen und zeigen, dass die reflexive Weg-Konstruktion insbesondere in ihrer Produktivität zwar deutlich hinter der reflexiven Bewegungskonstruktion und der reflexiven Partikelverbkonstruktion zurücksteht (dazu ausführlich Unterabschnitt 7.5.2), sie aber aufgrund ihrer formalen Charakteristika einerseits und nicht zuletzt aufgrund ihrer Sonderrolle bei der Evokation von Motion andererseits (dazu Unterabschnitt 8.3.2) als eigenständige Konstruktion zu betrachten ist.

In diesem Abschnitt beginne ich erneut mit dem Forschungsstand, den ich für die reflexive $W e g$-Konstruktion in Unterabschnitt 3.3.1 zusammenfasse. Besonders interessant sind die formalen Unterschiede zwischen ihr einerseits und der reflexiven Bewegungskonstruktion und reflexiven Partikelverbkonstruktion andererseits, die ich in Unterabschnitt 3.3.2 im Zuge der Betrachtung der Strukturelemente in den Blick nehme. 


\subsubsection{Forschungsstand}

Bisherige Untersuchungen zur reflexiven Weg-Konstruktion für das Deutsche kommen kaum ohne den Vergleich zu einer parallelen Konstruktion im Niederländischen aus. So diskutiert in einer Reihe von Arbeiten Verhagen (2002, 2003a,b,c) einerseits Parallelen zwischen niederländischen Konstruktionen mit dem prototypischen Verb banen und der way-Konstruktion, zeigt bisweilen andererseits aber auch Verbindungen zum Deutschen auf. So weist etwa Verhagen (2003a: 344-345, 2003c: 232-234) auf die vollständige formale (und bisweilen auch semantische) Übereinstimmung der reflexiven Weg-Konstruktion mit ihrem niederländischen Pendant hin, insbesondere hinsichtlich ihrer formalen Struktur, die ein Reflexivum und eine NP mit dem Nomen Weg als Kopf beinhaltet sowie das Verb bahnen als prototypisches KtE des KE EREIGNIS. Im Rahmen ihrer Studie zu zwei niederländischen Äquivalenten der way-Konstruktion weist van Egmond (2009: 162) neben der reflexiven Bewegungskonstruktion auch auf die reflexive Weg-Konstruktion hin und geht davon aus, dass das Deutsche jene beiden Äquivalente zur way-Konstruktion besitzt.

Die reflexive Weg-Konstruktion ist damit nach der reflexiven Bewegungskonstruktion, insbesondere für das Niederländische, aber auch für das Deutsche, eine Konstruktion, die gelegentlich - noch vor der reflexiven Partikelverbkonstruktion - als weiteres Äquivalent zur way-Konstruktion diskutiert wird. So überprüft Smirnova (2018: 23-25) auf Grundlage der formalen Identität zur way-Konstruktion, ob sie überhaupt als eigenständige Konstruktion angenommen werden kann, tendiert aber dazu, „die Existenz eines schematischen und produktiven Musters, das analog zu der englischen way- oder niederländischen weg-Konstruktion aufgebaut wäre, in Zweifel zu ziehen." (Smirnova 2018: 24). Aufgrund der niedrigen Produktivität der Konstruktion kommt sie, wie später Mortelmans \& Smirnova (2020: 59-60), zu dem Ergebnis, ,dass die Weg-Konstruktion als eigenständige Konstruktion im Deutschen kaum etabliert ist.“ (Smirnova 2018: 25).

Im diametralen Gegensatz dazu sieht McColm (2019: 38-42) die reflexive WegKonstruktion als primäres deutsches Äquivalent zur englischen way-Konstruktion an, während er die reflexive Bewegungskonstruktion lediglich als verwandt einordnet. Wie erwähnt, steht dieser Auffassung die Annahme von Mortelmans \& Smirnova (2020: 59-60) und auch Smirnova (2018: 25) gegenüber, die nicht davon ausgehen, dass es sich bei der reflexiven Weg-Konstruktion um eine eigenständige und zur way-Konstruktion äquivalente Konstruktion handelt. Den Grund dafür sehen sie in dem auch schon von Smirnova (2018: 24) festgestellten Befund, ,that instances of the pattern with the noun Weg are indeed very rare and occur almost exclusively with the verb bahnen“ (Mortelmans \& Smirnova 2020: 60). Beide Beob- 
achtungen lassen sich durch meine Korpusrecherchen grundsätzlich bestätigen, aber zugleich ausdifferenzieren.

Um die nahezu widersprüchlichen Ergebnisse von McColm (2019) einerseits und Smirnova (2018) und Mortelmans \& Smirnova (2020) andererseits zu vereinen, möchte ich für alle folgenden Überlegungen davon ausgehen, dass die reflexive Weg-Konstruktion trotz ihrer enorm niedrigen Token-Frequenz und Produktivität als ein Äquivalent zur way-Konstruktion zu betrachten ist. Das Auftreten einer zur englischen Konstruktion nahezu identischen Konstellation von Strukturelementen ist bereits ein gewichtiges Argument dafür. Ein weiteres ist, dass sich auch für das Niederländische, wie Mortelmans \& Smirnova (2020: 59) im Anschluss an van Egmond (2009) selbst zeigen, mindestens zwei ${ }^{52}$ Konstruktionen differenzieren lassen, die sich als Äquivalente der reflexiven Bewegungskonstruktion und der reflexiven Weg-Konstruktion verstehen lassen. Nicht zuletzt aus diesen beiden Gründen ist die reflexive Weg-Konstruktion auch im Deutschen als eigenständige Konstruktion zu betrachten.

\subsubsection{Strukturelemente}

Mit der reflexiven Bewegungskonstruktion teilt die reflexive Weg-Konstruktion die KE BEWEGEndes und EREIGNIS sowie das KEE. Das KE 〈WEG〉 ist für die reflexive Weg-Konstruktion wie für die reflexive Partikelverbkonstruktion als NichtKern-KE einzustufen, worin wiederum eine Parallele zu Letzterer besteht. Ein Unterschied zur reflexiven Bewegungskonstruktion und reflexiven Partikelverbkonstruktion und eine gleichzeitige Parallele zur way-Konstruktion besteht darin, dass zu dem KEE, das wie bei der reflexiven Bewegungskonstruktion und der reflexiven Partikelverbkonstruktion durch ein Reflexivum instanziiert wird, ein KorE in der Form einer NP mit der LE Weg oder semantisch verwandten anderen Nomen als Kopf hinzukommt. Diese Form teilt das KorE mit dem KEE der way-Konstruktion (vgl. dazu auch Unterabschnitt 2.3.2). Hinsichtlich der Strukturelemente besteht der einzige Unterschied zur reflexiven Bewegungskonstruktion in dem für die reflexive Weg-Konstruktion zusätzlichen KorE. Hinzu kommt allerdings die charakteristische Beschränkung, dass das Reflexivum im Dativ und nicht (wie bei den anderen Konstruktionen) im Akkusativ realisiert wird. Dies

52 Ob auch eine dritte, intransitive und nicht-reflexive Konstruktion, die Mortelmans \& Smirnova (2020: 59) nennen, für das Deutsche dazu zu zählen ist, muss an dieser Stelle offen bleiben. 
liegt offensichtlich daran, dass die NP, die das KorE bildet, bereits im Akkusativ steht. ${ }^{53}$

Die Strukturelemente der Konstruktion stellen sich in der Annotation der im Eingang zu diesem Abschnitt zitierten Belege (58)-(62) wie in (63)-(67) dar.

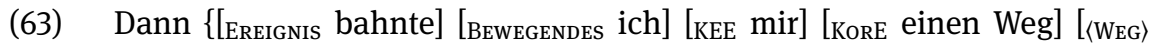
durch allerlei Buschwerk und trockenes Gehölz]\}. (Düffel, John von: Vom Wasser, München: dtv 2006, S. 214)

(64) \{[Bewegendes Mein Schälmesser mit der dünnen Klinge] [EREIGNis säbelt] [[KEE sich] [KoRE einen Weg] [〈WEG $\rangle$ durch die buschigen Petersilienköpfe]\}, während ich überlege, ob es tatsächlich Köpfe oder doch Blätter oder gar Büschel heißt. (Riedel, Susanne: Eine Frau aus Amerika, Berlin: Berlin Verlag 2003, S. 106)

(65) Längst müssen \{[KEE sich] [Bewegendes die hölzernen Schubkarren] [KoRE einen Weg] [〈WEG zwischen den Fässern] [EReIgnis bahnen]\}. (Die Zeit, 30.03.2000, Nr. 14)

(66) Als doppelter Fremder, der von einer fernen Insel und aus einer anderen Zeit kommt, \{[EReignis bahnt] [Bewegendes er] [KeE sich] zielstrebig [KorE den Weg] [〈WEG $\rangle$ zum Mörder seiner Tochter]\}. (Die Zeit, 05.01.2000, Nr. 2)

(67) In dieser Sekunde trat, überraschend und effektvoll, meine Mutter durch die Tür des Wintergartens, \{[EReIgnis bahnte] [KEE sich] [KoRE einen Weg] [〈WEG $\rangle$ zwischen den Adjutanten hindurch]\}. (Krausser, Helmut: Eros, Köln: DuMont 2006, S. 48)

Das KorE ist im Gegensatz zur reflexiven Bewegungskonstruktion ein Charakteristikum der reflexiven Weg-Konstruktion, weshalb ich es gleich zu Beginn der Illustration dieser Konstruktion etwas ausführlicher in den Blick nehmen möchte. Ziem, Flick \& Sandkühler (2019: 69) weisen bei der Definition des Strukturelements des KorE darauf hin, „that expressions functioning as CoRE do not have the

53 Welche semantischen Konsequenzen dieser Kasusunterschied zwischen dem KEE und dem KorE der reflexiven Weg-Konstruktion hat, muss offen bleiben. Denkbar ist, dass das Reflexivum dadurch mit der semantischen Rolle eines Benefizienten assoziiert wird (vgl. auch Hoherz 2017: 304), was die Konstruktion in die Nähe von Ditransitiv-Konstruktionen (Goldberg 1995: 141-151) rücken lässt bzw. das Reflexivum als freier Dativ (Eisenberg 2013: 290-296; Hentschel \& Weydt 2013: 164-171; Duden 2016: 831) angesehen werden kann. Bei FrameNet ist entsprechend für manche Frames (z.B. Building) das extrathematische FE BENEFICIARY dokumentiert, das sich in Motion, dem Konstruktions-Frame der reflexiven Weg-Konstruktion, allerdings nicht findet. $\mathrm{Zu}$ dieser Rolle von extrathematischen FE vgl. auch Fillmore \& Baker (2010: 325, Anm. 4) sowie Fillmore (2007: 134), Ruppenhofer et al. (2016: 24) und Boas (2016: 58). 
status of a CE.“ Gleichzeitig aber ist das KorE nicht mit einem KEE gleichzusetzen, da es im Falle der reflexiven Weg-Konstruktion eine geringere lexikalische (nicht aber formale) Varianz aufweist. Allerdings teilt das KorE mit dem KEE der reflexiven Weg-Konstruktion, welches analog zu demjenigen in der reflexiven Bewegungskonstruktion und der reflexiven Partikelverbkonstruktion definiert ist, die Eigenschaft, dass es nicht aus einem über alle Konstrukte invariant fixierten Element besteht, sondern eine gewisse Varianz aufweist. So variiert die Form der NP mit dem Kopf Weg (oder semantisch verwandten Nomen) je nachdem, welche weiteren Elemente diesem vorangestellt werden. ${ }^{54}$ Der dem Kopf vorangestellte Artikel kann entweder als Definitartikel, wie in (68), als Indefinitartikel, wie in (69), oder als Possessivartikel, wie in (70), erscheinen (vgl. für eine ähnliche Klassifikation Verhagen 2003a: 345, 2003c: 232-233; Mortelmans \& Smirnova 2020: 60).

(68) Wie ein Triumphator \{bahnt sich Schiller [KoRE den Weg] durch die Menschenmenge\}, eskortiert von den Würdenträgern der Universität. (Safranski, Rüdiger: Friedrich Schiller, München Wien: Carl Hanser 2004, S. 311)

(69) a. \{Mein Schälmesser mit der dünnen Klinge säbelt sich [KoRE einen Weg] durch die buschigen Petersilienköpfe\}, während ich überlege, ob es tatsächlich Köpfe oder doch Blätter oder gar Büschel heißt. (Riedel, Susanne: Eine Frau aus Amerika, Berlin: Berlin Verlag 2003, S. 106)

b. Ich beobachtete, wie Doreen die Hände des Pfarrers und seiner Frau abwehrte, sie ließ die beiden zurück und \{bahnte sich [KoRE einen Weg] zu den Essenswagen\}. (Franck, Julia: Lagerfeuer, Köln: DuMont Literatur und Kunst Verlag 2003, S. 301)

c. In dieser Sekunde trat, überraschend und effektvoll, meine Mutter durch die Tür des Wintergartens, \{bahnte sich [KoRE einen Weg] zwischen den Adjutanten hindurch\}. (Krausser, Helmut: Eros, Köln: DuMont 2006, S. 48)

(70) a. Jawohl, denn die Damen wirken „schwerfällig und lustlos“, \{bahnen sich an Bord nur mühsam [KoRE ihren Weg] durch die engen Gänge\} und ecken sehr wahrscheinlich auch bei solchen Passagieren an, die es in höchstem Maße unerquicklich finden, ihren Anisschnaps von einem Fesselballon serviert zu bekommen. (Die Zeit, 10.02.2000, Nr. 7)

54 Eine darüber hinausgehende Modifikation des Nomens, wie sie für die way-Konstruktion zu beobachten ist (vgl. etwa Goldberg 1995: 206, 1996: 38), ist in meinen Daten nicht belegt. Gleiches gilt für die Daten von McColm (2019: 40, 237). 
b. Doch er blieb nicht stehen, sondern \{bahnte sich [KorE seinen Weg] um den Tisch herum\}. (Düffel, John von: Houwelandt, Köln: DuMont Literatur und Kunst Verlag 2004, S. 43)

c. Was passiert ist, ist passiert“, und er drehte sich um und \{bahnte sich langsam durch die Büsche [KoRE seinen Weg] zurück zum Gutshaus\}. (Boie, Kirsten: Skogland, Ort: Hamburg 2005, S. 185)

Zwar sind die formalen Variationen des KorE in dieser Hinsicht stärker als die des KEE, hinsichtlich der lexikalischen Varianz aber ist es eingeschränkter, da der Kopf der es instanziierenden NP fast ausschließlich auf das Nomen Weg beschränkt ist. Somit handelt es sich bei den Konstrukten der reflexiven Weg-Konstruktion ebenfalls um Allokonstrukte im Sinne von Bücker (2014: 131), denen dieselbe Konstruktion zugrunde liegt. ${ }^{55}$ Diese Annahme ist auch dann aufrechtzuerhalten, wenn man beobachten kann, dass als Kopf der NP, die das KorE instanziiert, nicht nur das Nomen Weg auftreten kann, sondern auch andere, semantisch verwandte Nomen belegt sind. Wie die Belege (71) und (72) zeigen, sind zwei weitere Nomen belegt: Pfad und Trampelpfad.

(71) \{Paul mußte sich [KorE einen Pfad] zum Holzhaus bahnen\}. (Koneffke, Jan: Paul Schatz im Uhrenkasten, Köln: DuMont Buchverlag 2000, S. 77)

$\{[$ KorE Der Trampelpfad], den Jorge sich in Jahren gebahnt hatte\}, war verschwunden, das Wasser hatte ihn genommen. (Düffel, John von: Houwelandt, Köln: DuMont Literatur und Kunst Verlag 2004, S. 293)

Die Ansetzung des KorE als zusätzliches Strukturelement ist notwendig, da eine nicht-reflexive Variante der Konstruktion ohne das KEE auskommt und allein die NP mit Weg als Kopf als KorE besitzt. Die Belege in (73) sind Beispiele für das Verb bahnen in dieser Konstruktion. ${ }^{56}$

a. Fünf Minuten knapp sprach sie, dann nickte Pardell mehrmals und bahnte einen Weg durch die Bevölkerung des Gran Tour, die Frau folg-

55 Gruzitis et al. (2015: 51) sprechen davon, dass eine Konstruktion „alternative LUs“ enthalten kann, was der Vorstellung variierender Köpfe des KorE der reflexiven Weg-Konstruktion nahekommt. Allerdings gehen sie noch weiter: „If a CE [hier: ein KorE, A.W.] is represented by a fixed set of LUs, we assume that they are interchangeable (synonymous). “(Gruzitis et al. 2015: 51). Auch wenn LE wie Weg, Pfad und Trampelpfad gewiss nicht synonym sind, evozieren sie (wenngleich über Umwege) dennoch denselben Frame - eine Gemeinsamkeit, die sich für die Frage nach der Evokation eines mit der Konstruktion als Ganzes evozierten Frames nutzbar machen lässt (dazu Unterabschnitt 8.3.2).

56 Die Belege stammen aus der Suchanfrage für das Verb bahnen, die auch dessen Verwendung ohne Reflexivum erfasst, vgl. Unterabschnitt 3.4.2. 
te ihm. (Kopetzky, Steffen: Grand Tour, Frankfurt am Main: Eichborn 2002, S. 504)

b. Wer sich dennoch einen Menschen vorstellen möchte und seinen eigenen Weg durch die Kapitel bahnt, kommt mit dieser gewaltigen Bestandsaufnahme weiter als je zuvor. (Die Zeit, 23.03.2000, Nr. 13)

c. Ich nahm seine Fährte auf und bahnte meinen Weg durch den Sand, vorbei an den flanierenden Pärchen und wasserscheuen Zauderern, die bis zu den Knien auf die Wellen zustaksten, um dann wieder das Trockene zu suchen. (Düffel, John von: Vom Wasser, München: dtv 2006, S. 245)

Das oben in (72) zitierte Konstrukt zeigt zudem, dass das KE 〈WEG〉 ebenso wie dasjenige der reflexiven Partikelverbkonstruktion als Nicht-Kern-KE einzustufen ist, da es auch in der reflexiven Weg-Konstruktion uninstanziiert bleiben kann.

Die Strukturelemente der reflexiven Weg-Konstruktion lassen sich, in teilweiser Analogie zur reflexiven Bewegungskonstruktion, wie in Tabelle 3.3 dargestellt zusammenfassen. Die für die reflexive Bewegungskonstruktion vorgenommenen Änderungen im Gegensatz zur konstruktikographischen Beschreibung der wayKonstruktion im FrameNet-Konstruktikon (vgl. Unterabschnitt 3.1.2) gelten für die Strukturelemente der reflexiven Weg-Konstruktion analog.

Tab. 3.3: Strukturelemente der reflexiven Weg-Konstruktion

\begin{tabular}{|c|c|}
\hline Strukturelement & Vorläufige Definition \\
\hline BEWEGENDES & $\begin{array}{l}\text { Die KtE dieses KE referieren auf eine (belebte oder unbelebte) Entität, die ei- } \\
\text { ne ,Bewegung' ausführt. Die Entität, auf die ein KtE dieses KE referiert, muss } \\
\text { mit derjenigen, auf die das KEE referiert, identisch sein. }\end{array}$ \\
\hline EREIGNIS & $\begin{array}{l}\text { Die KtE dieses KE referieren auf ein Ereignis, das als eine ,Bewegung‘ der } \\
\text { Entität, auf die die KtE des KE BEWEGENDES referieren, verstanden werden } \\
\text { kann oder mit dieser ,Bewegung' einhergeht. }\end{array}$ \\
\hline KEE & $\begin{array}{l}\text { Das KEE wird durch ein Reflexivum (im weitesten Sinne) im Dativ instanziiert. } \\
\text { Dabei kann es sich um das, echte‘ Reflexivpronomen sich oder ein reflexiv ge- } \\
\text { brauchtes Personalpronomen in } 1 \text {. oder } 2 \text {. Person handeln. Handelt es sich } \\
\text { um Letzteres, muss es auf dieselbe Entität wie das KtE des KE BEWEGENDES } \\
\text { referieren. }\end{array}$ \\
\hline KorE & $\begin{array}{l}\text { Das KorE besteht aus einer NP mit dem Nomen Weg oder einem semantisch } \\
\text { verwandten Nomen als Kopf sowie einem Definit-, Indefinit- oder Possessi- } \\
\text { vartikel. }\end{array}$ \\
\hline$\langle\mathrm{WEG}\rangle$ & $\begin{array}{l}\text { Die KtE dieses Nicht-Kern-KE spezifizieren die räumliche Ausdehnung der } \\
\text {,Bewegung، der Entität, auf die das KtE des KE BEWEGENDES referiert. Da es } \\
\text { sich um ein Nicht-Kern-KE handelt, kann es uninstanziiert bleiben. }\end{array}$ \\
\hline
\end{tabular}


Ein wesentlicher Grund, die reflexive Bewegungskonstruktion und nicht die reflexive Weg-Konstruktion als semantisch primäres, aber nicht vollständig formales Äquivalent zur way-Konstruktion zu betrachten, ist die in der Forschung wiederholt erwähnte schwache Produktivität der reflexiven Weg-Konstruktion, die zur Annahme einer größeren semantischen Kompositionalität ihrer Konstrukte als derjenigen der reflexiven Bewegungskonstruktion führt (vgl. Smirnova 2018: 25; Mortelmans \& Smirnova 2020: 59-60). Die schwache Produktivität bestätigt sich bereits bei einem Blick auf die Datenlage (Unterabschnitt 3.4.2). So finden sich mit meinen Suchanfragen im DWDS-Kernkorpus 21 insgesamt lediglich 41 Treffer, von denen nach Abzug von Dubletten 27 Belege mit Konstrukten der reflexiven Weg-Konstruktion übrig bleiben. Für eine geringe Produktivität spricht neben dieser niedrigen Frequenz der Konstruktion insgesamt die sehr beschränkte Auswahl an LE, die das KE EREIGNIS als KtE instanziieren: Prototypisch erscheint hier das Verb bahnen, andere Verben sind zwar möglich, aber nur selten belegt (vgl. Verhagen 2003b: 35-36, 2003c: 232; Smirnova 2018: 24-25). Für die niederländische Entsprechung der Konstruktion kann das Verb banen bereits als Äquivalent zum englischen Verb make angesehen werden (vgl. Verhagen 2002: 411-412, 2003a: 333, 2003b: 36, 2003c: 225). Die von mir erhobenen Korpusdaten bestätigen den prototypischen Status des Verbs bahnen (Unterabschnitt 3.4.2): Unter den erwähnten 27 Konstrukten der reflexiven Weg-Konstruktion enthalten 26 das Verb bahnen, als einzig anderes Verb erscheint das mit Beleg (59) bereits zitierte säbeln. ${ }^{57}$ Auf einen Vergleich der Produktivität der reflexiven Weg-Konstruktion mit der reflexiven Bewegungskonstruktion und der reflexiven Partikelverbkonstruktion komme ich unter Anwendung einer konstruktionssemantischen Methode zur Messung der Produktivität in Unterabschnitt 7.5.2 zurück.

Der prototypische Status des Verbs bahnen ist einer der ausschlaggebenden Punkte, den für die semantischen Eigenschaften relevanten Frame der reflexiven Weg-Konstruktion wie denjenigen der reflexiven Bewegungskonstruktion und der reflexiven Partikelverbkonstruktionen mit Motion $\mathrm{zu}$ identifizieren. Motion kommt allerdings nicht erst als Frame, der mit der Konstruktion als Ganzes assoziiert werden kann, infrage, sondern kann bereits als Grundlage der lexikalischen Bedeutung des Verbs bahnen betrachtet werden. Für das Verb bahnen existiert zwar keine direkte englische Übersetzung, die als LE des Frames infrage käme (und die damit auch nicht in FrameNet verzeichnet ist), ${ }^{58}$ dass in den Konstrukten der reflexiven Weg-Konstruktion allerdings die semantische Komponente einer

57 Es ist also - wenngleich nur mit dieser wenigen Evidenz - keineswegs davon auszugehen, dass „bahnen is the only verb occuring in this construction“ (Mortelmans \& Smirnova 2020: 60). 58 Das im FrameNet dokumentierte Verb pave.v, das als mögliche Übersetzung von bahnen infrage käme (vgl. etwa die Übersetzung bei Mortelmans \& Smirnova 2020: 60), findet sich als LE 
,Bewegung' enthalten ist, sehe ich insbesondere durch das KorE als gegeben an. So evoziert die LE Weg (way.n) zwar Self_motion, da aber die KtE des KE BEWEGENDES, das mit dem FE Self_motion.SELF_MOVER identifiziert werden kann, nicht ausschließlich auf belebte Entitäten referiert, wie es die Definition des FE vorgibt, ziehe ich (neben weiteren Gründen) Motion vor, der in dieser Hinsicht neutral ist (vgl. weiterhin Unterabschnitt 8.3.2). Der bereits oben als (64) zitierte Beleg (74) gibt ein Beispiel für die Referenz eines KtE des KE BEWEGENDES auf eine solche unbelebte Entität.

(74) \{[Bewegendes Mein Schälmesser mit der dünnen Klinge] säbelt sich einen Weg durch die buschigen Petersilienköpfe\}, während ich überlege, ob es tatsächlich Köpfe oder doch Blätter oder gar Büschel heißt. (Riedel, Susanne: Eine Frau aus Amerika, Berlin: Berlin Verlag 2003, S. 106)

Weitere Gründe für Motion als Frame, der mit der reflexiven Weg-Konstruktion assoziiert werden kann, erörtere ich in den Unterabschnitten 8.3.2 und 8.5.2.

\subsection{Korpus und Datenauswahl}

Zum Abschluss dieses Kapitels möchte ich die Datengrundlage vorstellen, die ich für alle Analysen der drei in dieser Arbeit untersuchten Konstruktionen heranziehe. In Unterabschnitt 3.4.1 gehe ich auf das verwendete Korpus ein und skizziere die Suchanfragen für die drei untersuchten Konstruktionen. In Unterabschnitt 3.4.2 stelle ich das Verfahren zur Datenauswahl vor, da die für die Untersuchung relevanten Konstrukte der drei Konstruktionen manuell aus den Korpusdaten herausgefiltert werden müssen - ein Vorgang, der selbst einen methodologischen Erkenntnisgewinn verspricht (dazu Unterabschnitt 8.4.2). Ebenso gehe ich in diesem Zuge auf die Annotation der Daten ein, die die Grundlage für alle konstruktionssemantischen Analysen darstellt. Im Laufe der Arbeit werde ich an einigen wenigen Stellen zudem Daten heranziehen, die über die drei untersuchten Konstruktionen hinausgehen, weshalb ich in Unterabschnitt 3.4.3 auf diese eingehe.

für die Frames Distributed_position und Filling und damit in einer anderen als für die reflexive Weg-Konstruktion relevanten Lesart. Auf Konsequenzen der Identität des Frames, den bahnen evoziert, mit dem Konstruktions-Frame Motion für die Evokation des Letzteren gehe ich in Unterabschnitt 8.2.1 ein. 


\subsubsection{Korpus}

Als Quelle für authentische Belege von Konstrukten der reflexiven Bewegungskonstruktion, der reflexiven Partikelverbkonstruktion und der reflexiven WegKonstruktion nutze ich das Kernkorpus 21 des Digitalen Wörterbuchs der deutschen Sprache (DWDS). ${ }^{59}$ Es ist mit einer Größe von knapp 15,5 Millionen Token ${ }^{60}$ noch klein genug, um es mit einzelnen Suchanfragen exhaustiv zu durchsuchen und jeweils alle einsehbaren Treffer zu exportieren. ${ }^{61}$ Gleichzeitig ist es „ein zeitlich und nach [...] Textsorten differenziertes, derzeit aber noch nicht ausgewogenes Korpus“ (Geyken et al. 2017: 330) und bietet damit eine Bandbreite an Textsorten, zu denen neben Zeitungstexten, wissenschaftlicher Literatur und Gebrauchsliteratur vor allem belletristische Literatur zählt. ${ }^{62}$

Um möglichst viele Daten in Form von Belegen mit Konstrukten aller drei Konstruktionen zu erhalten, habe ich für jede Konstruktion spezifische Suchstrategien verwendet. Für die reflexive Bewegungskonstruktion stehen die Präpositionen, die als Köpfe der KtE des KE Weg dienen, im Zentrum, während die Suchanfragen für die reflexive Partikelverbkonstruktion um die unterschiedlichen Verbpartikeln zentriert sind. Für die reflexive Weg-Konstruktion habe ich eine Kombination unterschiedlicher Strategien verwendet.

Um Belege für die reflexive Bewegungskonstruktion im DWDS-Kernkorpus 21 zu finden, habe ich Suchanfragen getrennt nach Präpositionen, die als Köpfe der KtE des KE WEG infragekommen, durchgeführt. Hierfür habe ich aus den in der Duden-Grammatik (Duden 2016) aufgelisteten lokalen Präpositionen zunächst diejenigen ausgewählt, die dort als akkusativregierend beschrieben sind. Dies sind an, auf, bis, durch, gegen, hinter, in, neben, über, um, unter, vor und zwischen (vgl. Duden 2016: 616-619). Darüber hinaus habe ich fünf weitere Präpositionen ausgewählt, die laut Duden (2016: 623) zwar Dativ regieren, aber ebenso „Rich-

59 https://www.dwds.de/ (zuletzt abgerufen am 07.09.2021).

60 Vgl. https://www.dwds.de/r (zuletzt abgerufen am 07.09.2021) für aktuelle Daten zu allen Korpora des DWDS.

61 Die maximal exportierbare Menge an Belegstellen liegt im DWDS bei 5.000. Dies ist ein Argument für getrennte Suchanfragen, deren jeweilige Treffermengen für die drei untersuchten Konstruktionen stets unter diesem Wert liegen und damit vollständig exportiert werden können.

62 Aufgrund dieser Vielfalt an Textsorten nehme ich bei der orthographischen Wiedergabe der Belege eine Vereinheitlichung vor: Anführungszeichen werden gegenüber eventuell abweichender Originaldarstellungen stets in der Form „“ wiedergegeben, auch wenn, insbesondere in den literarischen Quellen, im Original andere Formen wie » oder "' verwendet werden. Die Quellenangaben der Belege gebe ich indes unverändert in der Form, in der sie sich im DWDS-Kernkorpus 21 befinden, wieder. 
tungsangaben“ markieren: $a b$, aus, nach, von und $z u .{ }^{63} \mathrm{Im}$ DWDS-Kernkorpus 21 habe ich für jede dieser Präpositionen für den gesamten Zeitraum (2000-2010) nach linearen Abfolgen von finitem Verb, ${ }^{64}$ Reflexivum und der jeweiligen Präposition mit einem maximalen Abstand von 10 Wörtern zum Reflexivum gesucht. ${ }^{65}$

Die Zusammenstellung der Korpusdaten für die reflexive Partikelverbkonstruktion ist weitgehend analog zu derjenigen der reflexiven Bewegungskonstruktion. Wie für Letztere habe ich auch für die reflexive Partikelverbkonstruktion separate Suchanfragen durchgeführt, nun getrennt nach Verbpartikeln. Die Auswahl der Partikeln erfolgte wiederum nach dem in Duden (2016: 708-713) aufgelisteten Inventar. Ausgeschlossen wurden allerdings insbesondere Partikeln auf nominaler Basis (z.B. acht, preis, stand) sowie die einfachen präpositionalen Partikeln gegen und wider, sofern sie nicht als Erstglied einer der untersuchten (Doppel-)Partikeln auftreten (etwa als gegenüber). Für jede Partikel wurden zwei getrennte Suchanfragen durchgeführt, um einerseits ihre Realisierung in Distanzstellung zum Basisverb und andererseits ihre Kontaktstellung zum Basisverb zu erfassen. Als größtmöglicher Abstand zum Reflexivum wurden wie bei der reflexiven Bewegungskonstruktion 10 Wörter gewählt. Jede Partikel wurde in der Suchanfrage linkstrunkiert, um auch Doppelpartikeln zu erfassen, in denen die gesuchte Partikel als „base particle“ (McIntyre 2001: 2), also als Zweitglied auftritt. Da eine PP, die als KtE des KE 〈WEG〉 infrage kommt, kein obligatorischer Bestandteil eines Konstrukts ist, ist sie nicht in die Suchanfragen integriert. ${ }^{66}$

Die Daten zur reflexiven Weg-Konstruktionen setzen sich aus drei Quellen zusammen: Zunächst habe ich alle ihre Konstrukte, die bereits in der Korpusrecherche für die reflexive Bewegungskonstruktion irrelevanterweise erschienen sind, gesondert gesammelt. Darüber hinaus habe ich für die Konstruktion eine separate, nach ihrer formalen Struktur gerichtete Suchanfrage nach finitem Verb, Refle-

63 Wie Traugott \& Trousdale (2013: 76, 86) im Anschluss an Mondorf (2011: 402) für die wayKonstruktion argumentieren, ist diese direktionale Bedeutung der KtE des Strukturelements WEG kriterial für die Konstruktion.

64 Als finite Verben belasse ich auch Hilfs- und Modalverben in der Datenauswahl, wenn sie mit dem (infiniten) Vollverb ein komplexes Prädikat bilden. Dies gilt auch für die Datenauswahl zur reflexiven Partikelverbkonstruktion.

65 Beispiel-Suchanfrage für die Präposition $a b$ : "\$p=VVFIN \$p=PRF \#10 (ab with \$p=APPR)". Für alle anderen Suchanfragen muss lediglich die Präposition ausgetauscht werden.

66 Beispiel-Suchanfrage für die Partikel $a b$ in Distanzstellung: " \$p=VVFIN \$p=PRF \#10 *ab with $\$ p=P T K V Z$ ". Beispiel-Suchanfrage für dieselbe Partikel in Kontaktstellung: "\$p=PRF \#10 $\star a b *$ with $\$ p=V V F I N "$. Wie bei der reflexiven Bewegungskonstruktion muss für alle weiteren Suchanfragen lediglich ein Element ersetzt werden, in diesem Fall die Partikel. Um die Ergebnisse mit der reflexiven Bewegungskonstruktion vergleichbar zu halten, suche ich auch für die Kontaktstellung nur nach finiten Verben und klammere infinite Verben in Verbletztstellung aus. 
xivum, in einem Abstand von 10 Wörtern dem Nomen Weg sowie einer Präposition durchgeführt. ${ }^{67}$ Zusätzlich habe ich alle Treffer für das Verb bahnen im DWDSKernkorpus 21 ausgewertet. ${ }^{68}$

Um aus den jeweiligen Treffermengen potenziell relevante Konstrukte zu extrahieren, ist es nötig, die Daten gerade für die reflexive Bewegungskonstruktion und die reflexive Partikelverbkonstruktion manuell auszuwerten und so die Treffermengen entsprechend zu reduzieren, sodass möglichst viele einschlägige Konstrukte gefunden werden.

\subsubsection{Datenauswahl und Annotation}

Die Ergebnisse der Suchanfragen an das DWDS-Kernkorpus 21 enthalten für alle drei Konstruktionen teils große Mengen irrelevanter Treffer und Falschpositive, die zwar den formalen Eigenschaften der Konstruktionen entsprechen, aber aus semantischer Hinsicht nicht als ihre Konstrukte einzustufen sind. Deshalb ist eine manuelle Datenauswertung der Treffermengen nötig, für die ich insbesondere für die reflexive Bewegungskonstruktion und die reflexive Partikelverbkonstruktion ein mehrstufiges Verfahren angewendet habe, um die Treffermengen entsprechend zu reduzieren.

Obwohl die semantischen Eigenschaften der Konstruktionen ausschlaggebend sind, lassen sich die ursprünglichen Treffermengen bereits über einige formale Kriterien eingrenzen. Anders als Smirnova (2018: 27), die ihre Daten für die reflexive Bewegungskonstruktion von Beginn an nach einem semantischen Kriterium auswertet, das in etwa den in Unterabschnitt 3.1.4 paraphrasierten zwei semantischen Eigenschaften - die (i) ,Bewegung' des Referenzobjekts, auf das das KtE von BEWEGENDES referiert, auf einem ,Weg', welche (ii) mit ,Schwierigkeiten` oder ,Hindernissen' verbunden ist - entspricht, lege ich zunächst formale Kriterien zugrunde und grenze die Treffermengen damit in einem ersten Schritt ein.

Für die reflexive Bewegungskonstruktion finden folgende vier Kriterien Anwendung. ${ }^{69}$

67 Suchanfrage: " $p p=V V F I N \$ p=P R F \# 10$ Weg $\$ p=A P P R "$.

68 Suchanfrage: bahnen.

69 Vgl. Perek (2018: 71) für ähnliche Kriterien für die way-Konstruktion, wobei ich mich nicht in Vorhinein, wie er, auf eine der in Unterabschnitt 3.1.3 diskutierten Lesarten festlege. 
1. Das Reflexivum als KEE muss eindeutig das KtE des KE BEWEGENDEs als Antezedens besitzen. ${ }^{70}$ Es muss zudem Argument desselben Verbs, das bereits das KtE von BEwEGENDES als ein Argument besitzt, sein.

2. Die Präposition muss, um semantisch eine ,Direktionalität‘, also einen ,Weg“ zu kodieren, Akkusativ regieren, sofern es sich um eine Wechselpräposition handelt (vgl. Duden 2016: 616, 620-622; Zifonun, Hoffmann \& Strecker 1997: 2105). ${ }^{71}$ Fälle, in denen die Kasusrektion der Präposition ambig ist, werden zunächst in die Auswahl aufgenommen.

3. Die Präposition als Teil der KtE des KE WEG muss Kopf einer PP und als Argument von dem Verb, das bereits das KtE des KE BEwEGENDES und das KEE als Argumente besitzt, abhängig sein. Dies schließt unter anderem Partikelverben, in denen die (seitens des DWDS fälschlich als solche annotierte) Präposition eigentlich eine Verbpartikel ist, aus.

4. Eindeutige Instanzen anderer Konstruktionen, insbesondere der reflexiven Weg-Konstruktion, werden zunächst ausgeschlossen und gesondert gesammelt. Vollständig ausgeschlossen werden infinite Verbformen in Kombination mit einem Modal- oder Hilfsverb, Passiversatzformen sowie als Funktionsverbgefüge identifizierbare Instanzen, in denen dem Verb allein kaum eine lexikalische Bedeutung zukommt.

Nach Anwendung dieser Kriterien reduzieren sich die Treffermengen für die einzelnen Präpositionen teils erheblich, allerdings fallen hierunter noch nicht ausschließlich Belege mit Konstrukten der reflexiven Bewegungskonstruktion. Die Belege schließen noch immer Falschpositive ein, die zwar den vier oben genannten formalen Kriterien entsprechen, semantisch gesehen aber keine relevanten Konstrukte zeigen. Diese Falschpositive sind interessant, weil sie durch den Kontrast zu den eigentlichen Konstrukten der reflexiven Bewegungskonstruktion die semantischen Eigenschaften dieser deutlicher zum Vorschein treten lassen (dazu Unterabschnitt 8.4.2). Um sie an späterer Stelle noch analysieren zu können, behalte ich sie deshalb in der Datenauswahl und ermögliche, auf sie zurückkommen

70 Dieses Kriterium ist deswegen wichtig, weil im DWDS-Kernkorpus 21 zahlreiche Pronomen fälschlich als Reflexiva annotiert sind, bei denen es sich tatsächlich aber nicht um Reflexiva handelt.

71 Auf dieses Kriterium verweisen explizit auch Perek \& Hilpert (2014: 270). Dagegen bezweifelt Smirnova (2018: 35) eine formale Restriktion hinsichtlich der Präposition und sieht sogar das Kriterium der Direktionalität als zu restriktiv an. 
zu können, ohne dass sie mit den tatsächlichen Konstrukten der Konstruktion verwechselt werden könnten. ${ }^{72}$

In Tabelle 3.4 sind die Daten zu allen untersuchten Präpositionen der reflexiven Bewegungskonstruktion nach Präpositionen geordnet zusammengefasst. In der zweiten Spalte sind alle Treffer, die die jeweilige Suchanfrage einer Präposition ergeben hat, angegeben, während in der dritten Spalte die ausgewählten Belege (inklusive Falschpositive) angegeben sind. Insgesamt habe ich aus den 13.416 Treffern aller Präpositionen 5.173 Belege ausgewählt. Diese Menge schließt Konstrukte der reflexiven Bewegungskonstruktion ebenso wie die erwähnten Falschpositive ein. In der vierten Spalte sind schließlich die relevanten Belege mit Konstrukten der reflexiven Bewegungskonstruktion verzeichnet, deren Auswahl durch die im Folgenden skizzierten semantischen Kriterien zustande kommt. Nach Anwendung dieser Kriterien ergibt sich eine Anzahl von 1.011 relevanten Belegen mit Konstrukten der reflexiven Bewegungskonstruktion.

Um die semantischen Falschpositive von den tatsächlichen Belegen für die reflexive Bewegungskonstruktion zu trennen und schließlich Letztere $\mathrm{zu}$ identifizieren, habe ich folgende semantische Annotationen vorgenommen. Alle Belege, die potenziell Konstrukte der reflexiven Bewegungskonstruktion enthalten, habe ich zunächst auf Frames hin annotiert: Dazu habe ich die LE, die als KtE das KE EREIGNIS instanziieren, in ihrer englischen Übersetzung in FrameNet 1.7 nachgeschlagen und, sofern eine entsprechende LE vorhanden ist, den Beleg nach dem Frame, der als Basis für die lexikalische Bedeutung der LE infrage kommt, annotiert. Anschließend habe ich die einzelnen KtE der KE BEWEGENDES und WEG sowie des KEE daraufhin annotiert, ob sie Instanzen eines FE dieses Frames, eines FE des Frames Motion oder beiden zugleich sind.

Diese Annotation bildet die Grundlage für die Entscheidung, ob ein fraglicher Beleg ein Konstrukt der reflexiven Bewegungskonstruktion enthält oder nicht. Darüber hinaus habe ich jeden relevanten Beleg global auf die Polysemie der Konstruktion hin annotiert, ob also eine neutrale Lesart, eine ,manner'-, ,means‘- oder ,incidental'-Lesart in dem jeweiligen Konstrukt vorliegt (zur Methode dafür vgl. Unterabschnitte 5.2.3 und 5.2.4). Eine weitere Annotationskategorie betrifft die Stärke der Koerzionseffekte, die in zahlreichen Konstrukten vorliegen und die Grundlage für die Ermittlung des Koerzionspotenzials der Konstruktion bilden (dazu Abschnitte 5.5 und 7.4). Schließlich habe ich für jedes Konstrukt

72 Die soeben skizzierten Kriterien konstituieren in dieser Hinsicht ein Muster im Sinne von Bücker (2014: 118-119), aus dem erst in einem nächsten Schritt Konstruktionen rekonstruiert werden können. Diesen Rekonstruktionsprozess sehe ich als wesentlichen empirischen Zugang zu den semantischen Eigenschaften der so festgestellten Konstruktion(en) an, weshalb er im weiteren Verlauf der vorliegenden Arbeit noch von Interesse sein wird. 
Tab. 3.4: Datengrundlage für die reflexive Bewegungskonstruktion

\begin{tabular}{lrrr}
\hline Präposition & Treffer & Ausgewählte Belege & Relevante Konstrukte \\
\hline$a b$ & 10 & 2 & 0 \\
an & 1.615 & 658 & 56 \\
auf & 2.130 & 911 & 119 \\
aus & 770 & 226 & 51 \\
bis & 90 & 10 & 3 \\
durch & 433 & 189 & 81 \\
gegen & 385 & 274 & 27 \\
hinter & 130 & 33 & 2 \\
in & 3.580 & 650 & 215 \\
nach & 692 & 246 & 75 \\
neben & 180 & 108 & 4 \\
über & 856 & 465 & 136 \\
um & 691 & 460 & 24 \\
unter & 289 & 22 & 11 \\
von & 1.585 & 410 & 48 \\
vor & 503 & 49 & 11 \\
zu & 822 & 432 & 131 \\
zwischen & 202 & 28 & 17 \\
\hline Gesamt & 13.416 & 5.173 & 1.011 \\
\hline & & &
\end{tabular}

annotiert, ob es die Interpretation des Aspekts einer ,Schwierigkeit‘ (vgl. Unterabschnitt 3.1.4) zulässt und wie diese Interpretation zustande kommt oder eventuell blockiert wird (dazu Abschnitt 5.7).

Wie für die reflexive Bewegungskonstruktion ist für die reflexive Partikelverbkonstruktion aufgrund einer hohen Anzahl irrelevanter Treffer in den Suchergebnissen ebenso eine manuelle Auswertung der Daten erforderlich. Diese erfolgte weitgehend analog zu derjenigen der reflexiven Bewegungskonstruktion, aufgrund der in den Unterabschnitten 3.2.2 und 3.2.3 dargestellten Unterschieden zwischen beiden Konstruktionen allerdings weniger restriktiv. Es ergeben sich drei Kriterien, die wie folgt definiert werden können.

1. Das Reflexivum, das das KEE instanziiert, muss sich wie bei der reflexiven Bewegungskonstruktion eindeutig auf das KtE des KE BEWEGENDES als Antezedens beziehen. Es muss ebenso Argument desselben Verbs, das bereits das KtE von BEWEGENDES als ein Argument besitzt, sein.

2. Fakultative PP, die als KtE des KE 〈WEG infrage kommen, werden - anders als für die reflexive Bewegungskonstruktion - nicht nach ihrem von der Präposition regierten Kasus differenziert, da die PP (wenn ihr Kopf eine Wechselpräposition ist) aufgrund des durch die Partikel bereits gegebenen direktionalen 
semantischen Aspekts auch im Dativ stehen darf (vgl. dazu Olsen 1996a: 274, 1997b: 18, 1999: 232-233).

3. Instanzen, die zugleich als Konstrukte der reflexiven Bewegungskonstruktion angesehen werden könnten, werden aus den in Unterabschnitt 3.2.3 geschilderten Gründen in der Datenauswahl belassen.

Wie bei der reflexiven Bewegungskonstruktion enthalten die so gewonnenen Daten noch immer semantische (nicht aber formale) Falschpositive, die nur durch eine frame-semantische Annotation von ,echten' Konstrukten der reflexiven Partikelverbkonstruktion unterschieden werden können. Ich behalte sie auch für die reflexive Partikelverbkonstruktion in der Datenauswahl. Die Anzahlen der einschlägigen Konstrukte pro Verbpartikel sind in Tabelle 3.5 in der vierten Spalte angegeben, während die beiden Spalten zuvor die gesamten Treffermengen der Suchanfragen sowie die nach den oben genannten drei Kriterien zunächst übrig gebliebenen Treffer angeben. In Tabelle 3.5 ist somit die gesamte Datengrundlage für die reflexive Partikelverbkonstruktion nach Partikeln geordnet zusammengefasst (der Asterisk steht für die Trunkierung in der Suchanfrage, die obligatorische Rechtstrunkierung bei Partikeln in Kontaktstellung ist nicht dargestellt).

Tab. 3.5: Datengrundlage für die reflexive Partikelverbkonstruktion

\begin{tabular}{lrrr}
\hline (Doppel-)Partikel & Treffer & Ausgewählte Belege & Relevante Konstrukte \\
\hline *ab (Distanzstellung) & 361 & 238 & 52 \\
*ab (Kontaktstellung) & 560 & 191 & 34 \\
*an (Distanzstellung) & 840 & 378 & 28 \\
*an (Kontaktstellung) & 2.088 & 179 & 8 \\
*auf (Distanzstellung) & 492 & 374 & 9 \\
*auf (Kontaktstellung) & 420 & 260 & 6 \\
*aus (Distanzstellung) & 538 & 395 & 30 \\
*aus (Kontaktstellung) & 522 & 333 & 4 \\
*bei (Distanzstellung) & 30 & 15 & 15 \\
*bei (Kontaktstellung) & 94 & 11 & 10 \\
*durch (Distanzstellung) & 84 & 64 & 23 \\
*durch (Kontaktstellung) & 84 & 39 & 12 \\
*ein (Distanzstellung) & 393 & 235 & 36 \\
*ein (Kontaktstellung) & 512 & 134 & 16 \\
*fort (Distanzstellung) & 32 & 23 & 1 \\
*fort (Kontaktstellung) & 24 & 16 & 3 \\
*frei (Distanzstellung) & 6 & 2 & 1 \\
*frei (Kontaktstellung) & 13 & 2 & 1 \\
\hline
\end{tabular}


Tab. 3.5 - fortgesetzt

\begin{tabular}{|c|c|c|c|}
\hline (Doppel-)Partikel & Treffer & Ausgewählte Belege & Relevante Konstrukte \\
\hline *heim (Distanzstellung) & 1 & 1 & 1 \\
\hline *heim (Kontaktstellung) & 5 & 0 & 0 \\
\hline *her (Distanzstellung) & 39 & 15 & 1 \\
\hline *her (Kontaktstellung) & 362 & 18 & 1 \\
\hline *hin (Distanzstellung) & 98 & 66 & 4 \\
\hline *hin (Kontaktstellung) & 192 & 22 & 3 \\
\hline *hinter (Distanzstellung) & 0 & 0 & 0 \\
\hline *hinter (Kontaktstellung) & 6 & 1 & 0 \\
\hline *hoch (Distanzstellung) & 18 & 5 & 4 \\
\hline *hoch (Kontaktstellung) & 13 & 3 & 3 \\
\hline${ }^{*}$ mit (Distanzstellung) & 14 & 4 & 1 \\
\hline${ }^{*}$ mit (Kontaktstellung) & 31 & 3 & 0 \\
\hline *nach (Distanzstellung) & 20 & 5 & 0 \\
\hline *nach (Kontaktstellung) & 25 & 2 & 0 \\
\hline *über (Distanzstellung) & 42 & 1 & 1 \\
\hline *über (Kontaktstellung) & 165 & 34 & 2 \\
\hline *um (Distanzstellung) & 450 & 427 & 238 \\
\hline${ }^{*} u m$ (Kontaktstellung) & 342 & 165 & 76 \\
\hline *unter (Distanzstellung) & 33 & 17 & 13 \\
\hline *unter (Kontaktstellung) & 157 & 85 & 3 \\
\hline *vor (Distanzstellung) & 286 & 135 & 68 \\
\hline *vor (Kontaktstellung) & 232 & 70 & 30 \\
\hline *weg (Distanzstellung) & 45 & 25 & 14 \\
\hline${ }^{*}$ weg (Kontaktstellung) & 156 & 7 & 2 \\
\hline${ }^{*} z u$ (Distanzstellung) & 240 & 100 & 54 \\
\hline${ }^{*} z u$ (Kontaktstellung) & 396 & 51 & 12 \\
\hline *zurück (Distanzstellung) & 234 & 177 & 28 \\
\hline *zurück (Kontaktstellung) & 91 & 51 & 2 \\
\hline Gesamt & 10.786 & 3.569 & 850 \\
\hline
\end{tabular}

Die semantische Annotation der Daten für die reflexive Partikelverbkonstruktion stellt sich analog zu derjenigen der reflexiven Bewegungskonstruktion dar. Auch hier habe ich den von dem KtE des KE EREIGNIS evozierten Frame, die instanziierten FE sowie die Lesart des Konstrukts, die Stärke des eventuell vorhandenen Koerzionseffekts und das Vorhandensein oder die Blockierung des Aspekts der ,Schwierigkeit" annotiert.

Die Daten der reflexiven Weg-Konstruktion setzen sich aus drei Quellen zusammen: aus den bereits für die reflexive Bewegungskonstruktion erhobenen Daten sowie aus den in Unterabschnitt 3.4.1 erwähnten Suchanfragen für die formale Struktur der reflexiven Weg-Konstruktion und das Verb bahnen. Da die Datenmen- 
gen jeweils sehr gering sind, ist ein detailliertes Verfahren zur Auswertung der Daten wie bei den anderen beiden Konstruktionen nicht nötig. Ausgewählt werden können stets Belege, die der formalen Struktur der Konstruktion entsprechen. Hinzu kommt, dass es bei dieser Art der Zusammenstellung der Korpusdaten zu einer größeren Anzahl von Dubletten kommt, bedingt durch die unterschiedlichen Datenquellen. Diese habe ich für alle weiteren Analysen ausgesondert. Die Ergebnisse sind in Tabelle 3.6 dargestellt.

Tab. 3.6: Datengrundlage für die reflexive Weg-Konstruktion

\begin{tabular}{lrr}
\hline Datenquelle & Treffer & Ausgewählte Belege \\
\hline Daten der reflexiven Bewegungskonstruktion & 13.416 & 7 \\
Spezifische formal-strukturelle Suchanfrage & 34 & 8 \\
Korpusrecherche für das Verb bahnen & 53 & 26 \\
\hline Gesamt & 13.503 & 41 \\
\hline abzüglich Dubletten & & 27 \\
\hline
\end{tabular}

Nichtsdestotrotz können auch für die reflexive Weg-Konstruktion einige irrelevante Treffer ausgesondert werden. Von vornherein ausgeschlossen habe ich Belege, die keine Instanzen von Reflexivkonstruktionen zeigen (vor allem unter den Daten für das Verb bahnen, wenn sie kein Reflexivum einschließen) sowie Belege, die eindeutige Instanzen anderer Konstruktionen sind. Da sich aufgrund der drei unterschiedlichen Suchstrategien Belege finden, die mehrmals erscheinen, habe ich die Daten für die reflexive Bewegungskonstruktion im Anschluss an die Suchanfragen zusammengeführt und Dubletten entfernt. Von den 41 vorausgewählten Treffern bleiben danach noch 27 Belege übrig. Diese bilden die Datengrundlage für die reflexive Weg-Konstruktion.

Aufgrund der im Vergleich zur reflexiven Bewegungskonstruktion und reflexiven Partikelverbkonstruktion sehr geringen Datenmenge für die reflexive WegKonstruktion habe ich die Annotation Letzterer auf den von einem KtE des KE EREIGNIS evozierten Frame, den nominalen Kopf des KorE (also Weg, Pfad oder Trampelpfad) sowie die mögliche Interpretation eines Aspekts der ,Schwierigkeit‘ beschränkt. Alle anderen wesentlichen Informationen lassen sich direkt aus der Datenauswahl ablesen. 


\subsubsection{Weitere Daten}

Neben den Daten für die reflexive Bewegungskonstruktion, die reflexive Partikelverbkonstruktion und die reflexive Weg-Konstruktion ziehe ich an einigen wenigen Stellen, insbesondere in Kapitel 5, vergleichend Daten zu einzelnen LE und anderen syntaktischen Konstruktionen heran. Diese entstammen, wie die Daten zu den drei schwerpunktmäßig untersuchten Konstruktionen, dem DWDSKernkorpus 21. Die Daten umfassen folgende zwei Treffermengen:

- $\quad 1.809$ Treffer zu einer Suchanfrage für die LE erscheinen, für die schlicht nach dem entsprechenden Wort gesucht wurde; ${ }^{73}$

- $\quad$ 3.119 Treffer zu einer Suchanfrage für die Subjekt-Auxiliar-Inversion (im Sinne von Goldberg 2006: 166-182), für die nach einem finiten Auxiliarverb am Satzanfang gesucht wurde. ${ }^{74}$

An anderen Stellen werde ich ebenso auf teils bereits in diesem Kapitel zitierte Daten zurückgreifen, die bei der Auswertung der Treffer für die drei schwerpunktmäßig untersuchten Konstruktionen als irrelevante Treffer oder (semantische) Falschpositive ausgesondert und nicht bereits zu den Daten einer anderen Konstruktion, vorrangig der reflexiven Weg-Konstruktion zugerechnet wurden. Hierzu zählen zwei Arten von Treffern:

- Belege, die zwar strukturell Konstrukten der reflexiven Bewegungskonstruktion entsprechen, semantisch aber nicht als ihre Konstrukte anzusehen sind;

- Belege für Konstrukte der nicht-reflexiven Variante der reflexiven Weg-Konstruktion, von denen einige bereits in Unterabschnitt 3.3.2 zitiert sind.

Diese zusätzlichen Daten ziehe ich allerdings, wie diejenigen zur LE erscheinen und der Subjekt-Auxiliar-Inversion, lediglich zu illustrativen und vergleichenden Zwecken heran, weshalb ich für sie keine quantitativen Auswertungen vornehme, sodass auf einen weiterführenden Überblick über sie verzichtet werden kann.

73 Suchanfrage: erscheinen.

74 Suchanfrage: $\$ p=V A F I N$ with $\$ .=0$. 